\title{
Using Bayesian Variable Selection Methods to Choose Style Factors in Global Stock Return Models
}

\author{
Anthony D. Hall \\ School of Finance and Economics, \\ University of Technology, Sydney, Australia \\ Soosung Hwang \\ Department of Applied Economics, University of Cambridge, UK \\ Stephen E. Satchell* \\ Faculty of Economics and Politics and Trinity College, \\ University of Cambridge, UK
}

January 2000

\begin{abstract}
This paper applies Bayesian variable selection methods from the statistics literature to give guidance in the decision to include/omit factors in a global (linear factor) stock return model. Once one has accounted for country and sector, it is possible to see which style or styles best explains current asset returns. The study suggests that global style is not an important component of risk once country and sector have been accounted for.
\end{abstract}

\section{Introduction}

There is considerable literature on the choice of factors in explaining asset returns at the global level, see Capaul, Rowley and Sharpe (1993), Arshanapalli, Coggin

${ }^{*}$ Corresponding Author: S. E. Satchell, Faculty of Economics and Politics, Austin Robinson Building, Sidgwick Avenue, Cambridge CB3 9DD, UK., TEL) 441223 335281, FAX) 441223 335475, E-MAIL) ses11@econ.cam.ac.uk. The second and third authors would like to thank Inquire (UK) for financial assistance. We would like to thank Alpha Strategies for providing us with the data. 
and Doukas (1998) and Fama and French (1998). Many models, however, have been global tactical asset allocation (GTAA) models, concentrating on country wide, or global, factors to try to explain the returns on equity indices. Some research has concentrated on global or regional models at the individual stock level, we call such models stock return models. Some literature, see Heston and Rouwenhorst (1995) and Kuo and Satchell (1998), has concentrated on ranking different taxonomies in explaining the variability of the data. The findings are that the factors that matter, in declining order of importance, are country factors, followed by sector factors, followed by style factors.

The purpose of this paper is to use Bayesian variable selection methods to further explore this question. This methodology gives a posterior probability that a particular style variable should be included, conditional on the sample data. In the particular case of the linear factor model, where residual errors are uncorrelated by assumption, this procedure simplifies to a closed form expression. It is found that this technique seems ideal for the problem in hand; it allows updating of "priors" recursively, so that style rotation can be taken into account; namely, the phenomenon that a particular style may have a risk-premium that changes through time. The factor selection procedure is illustrated by considering a set of style factors for the Morgan-Stanley Capital International (MSCI) universe of stocks.

\section{Bayesian SUR Model for the Selection of Fac- tors in Linear Factor Models ${ }^{1}$}

Consider the following $m$ regression equation system with $T$ observations,

$$
\mathbf{r}^{i}=\mathbf{X}^{i} \boldsymbol{\beta}^{i}+\mathbf{e}^{i} \text { for } i=1,2, \ldots m
$$

where $\mathbf{r}^{i}$ is a $(T \times 1)$ vector of the $T$ observations of the dependent variable, $\mathbf{X}^{i}$ is a $\left(T \times p^{i}\right)$ matrix of independent variables, $\boldsymbol{\beta}^{i}$ is a $\left(p^{i} \times 1\right)$ vector of the regression coefficients, and $\mathbf{e}^{i}$ is the vector of errors for the $T$ observations of the $i$ th regression. If the above system is a seemingly unrelated regressions (SUR) model, it can be assumed that the vector of the errors, $e^{i}$, is distributed as

$$
\mathbf{e} \sim N\left(0, \boldsymbol{\Sigma} \otimes \mathbf{I}_{T}\right)
$$

where $\mathbf{e}^{\prime}=\left(\mathbf{e}^{1 \prime}, \mathbf{e}^{2 \prime}, \ldots, \mathbf{e}^{m \prime}\right)$, and $\boldsymbol{\Sigma}$ is a positive definite $(m \times m)$ matrix to be estimated.

Introduce a new vector, $\gamma^{i \prime}=\left(\gamma_{1}^{i}, \gamma_{2}^{i}, \ldots, \gamma_{p^{i}}^{i}\right)$, whose element is a binary indicator variable, $\gamma_{n}^{i}$, that is, $\gamma_{n}^{i}=1$ if $\beta_{n}^{i} \neq 0$ and $\gamma_{n}^{i}=0$ if $\beta_{n}^{i}=0$, where $n$ and $i$ correspond to the $n$th element of the $i$ th regression. The interpretation of $\gamma_{n}^{i}=1$ is that it

\footnotetext{
${ }^{1}$ See Smith and Kohn (1998) for details of this section.
} 
indicates if factor $n$ is indeed in the model for the return of asset $i$. Then equation (1), conditioning on $\gamma^{i}$, is after removing the redundant terms with $\beta_{n}^{i}=0$,

$$
\mathbf{r}^{i}=\mathbf{X}_{\gamma^{i}}^{i} \boldsymbol{\beta}_{\gamma^{i}}^{i}+\mathbf{e}^{i}
$$

Define $q_{\gamma}^{i}=\sum_{n=1}^{p^{i}} \gamma_{n}^{i}$, then $\mathbf{X}_{\gamma^{i}}^{i}$ is a $\left(T \times q_{\gamma}^{i}\right)$ matrix and $\boldsymbol{\beta}_{\gamma^{i}}^{i}$ is a $\left(q_{\gamma}^{i} \times 1\right)$ vector. Therefore, by stacking the $m$ linear regressions, the SUR model can be presented as

$$
\widetilde{\mathbf{r}}=\widetilde{\mathbf{X}}_{\gamma} \widetilde{\boldsymbol{\beta}}_{\gamma}+\widetilde{\mathbf{e}}
$$

where $\widetilde{\mathbf{r}}^{\prime}=\left(\mathbf{r}^{1 \prime}, \mathbf{r}^{2 \prime}, \ldots, \mathbf{r}^{\mathbf{m} \prime}\right), \widetilde{\mathbf{X}}_{\gamma}=\left(\begin{array}{llll}\mathbf{X}_{\gamma^{1}}^{1} & \mathbf{0} & \cdots & \mathbf{0} \\ \mathbf{0} & \mathbf{X}_{\gamma^{2}}^{2} & \cdots & \mathbf{0} \\ & & \vdots & \mathbf{0} \\ \mathbf{0} & \mathbf{0} & \cdots & \mathbf{X}_{\gamma^{m}}^{m}\end{array}\right), \widetilde{\boldsymbol{\beta}}_{\gamma}=\left(\boldsymbol{\beta}_{\gamma^{1}}^{1}, \boldsymbol{\beta}_{\gamma^{2}}^{2}, \ldots, \boldsymbol{\beta}_{\gamma^{m}}^{m}\right)$, and $\widetilde{\mathbf{e}} \sim N\left(0, \boldsymbol{\Sigma} \otimes \mathbf{I}_{T}\right)$. Note that $\widetilde{\mathbf{X}}_{\boldsymbol{\gamma}}$ is a $\left(m T \times \sum_{i=1}^{m} q_{\gamma}^{i}\right)$ matrix and $\widetilde{\boldsymbol{\beta}}_{\boldsymbol{\gamma}}$ is a vector of $\sum_{i=1}^{m} q_{\gamma}^{i}$ elements.

As the above remarks indicate, the dependent variable, $\widetilde{\mathbf{r}}$, is asset returns and the independent variables, $\widetilde{\mathbf{X}}_{\gamma}$, are factors in asset pricing models. Assume that the set of factors are the same across all equations, i.e., $\mathbf{X} \equiv \mathbf{X}^{1}=\mathbf{X}^{2}=, \ldots,=\mathbf{X}^{m}$. It can also be assumed that the binary indicator variable vector, $\gamma^{i}$, is the same across all $m$ regression systems, i.e., $\boldsymbol{\gamma} \equiv \boldsymbol{\gamma}^{1}=\boldsymbol{\gamma}^{2}=, \ldots,=\boldsymbol{\gamma}^{m}$ and $q_{\gamma} \equiv q_{\gamma}^{1}=q_{\gamma}^{2}=, \ldots,=q_{\gamma}^{m}{ }^{2}$ Assume also that $\boldsymbol{\Sigma}$ is diagonal, i.e., $\mathbf{e}^{i} \sim N\left(0, \sigma_{i}^{2}\right)$ and $\operatorname{cov}\left(\mathbf{e}^{i}, \mathbf{e}^{j}\right)=0$ for $i \neq j$. These assumptions, which are standard in linear factor models, simplify the above SUR model to an ordinary least square (OLS) model in an univariate setting in the sense that generalised least squares (GLS) estimation is numerically equal to OLS estimation. Equation (3) can be rewritten as

$$
\mathbf{r}^{i}=\mathbf{X}_{\boldsymbol{\gamma}} \boldsymbol{\beta}_{\gamma}^{i}+\mathbf{e}^{i} \quad \forall i
$$

Now $\mathbf{X}_{\boldsymbol{\gamma}}$ is a $\left(T \times q_{\gamma}\right)$ matrix and $\boldsymbol{\beta}_{\gamma}^{i}$ is a vector of $q_{\gamma}$ elements.

The purpose of this study is to obtain the posterior probabilities of $\gamma$ for this linear factor model. The posterior joint probability density function is, by Bayes' law,

$$
\begin{aligned}
p d f\left(\boldsymbol{\beta}_{\gamma}^{i}, \sigma_{i}^{2}, \boldsymbol{\gamma} \mid \mathbf{r}^{i}\right) & =\frac{p d f\left(\mathbf{r}^{i} \mid \boldsymbol{\beta}_{\gamma}^{i}, \sigma_{i}^{2}, \boldsymbol{\gamma}\right) p d f\left(\boldsymbol{\beta}_{\gamma}^{i}, \sigma_{i}^{2}, \boldsymbol{\gamma}\right)}{p d f\left(\mathbf{r}^{i}\right)} \\
& \propto p d f\left(\mathbf{r}^{i} \mid \boldsymbol{\beta}_{\gamma}^{i}, \sigma_{i}^{2}, \boldsymbol{\gamma}\right) p d f\left(\boldsymbol{\beta}_{\gamma}^{i}, \sigma_{i}^{2}, \boldsymbol{\gamma}\right)
\end{aligned}
$$

where $\propto$ represents "is proportional to". The posterior joint density function, $p d f\left(\boldsymbol{\beta}_{\gamma}^{i}, \sigma_{i}^{2}, \boldsymbol{\gamma} \mid \mathbf{r}^{i}\right)$, in equation (5) needs the joint priors on the parameters, i.e.,

\footnotetext{
${ }^{2}$ The interpretation here is that, if $\gamma=(1,0,0, \ldots, 0)^{\prime}$, for example, then only factor one is included in the model for all equations, i.e., for all $i$. If $\gamma^{i}=(1,0,0, \ldots, 0)^{\prime}$, for example, then only factor one is included in the model for for a given $i$.
} 
$p d f\left(\boldsymbol{\beta}_{\gamma}^{i}, \sigma_{i}^{2}, \boldsymbol{\gamma}\right)$. Note that

$$
p d f\left(\boldsymbol{\beta}_{\boldsymbol{\gamma}}^{i}, \sigma_{i}^{2}, \boldsymbol{\gamma}\right)=p d f\left(\boldsymbol{\beta}_{\boldsymbol{\gamma}}^{i} \mid \sigma_{i}^{2}, \boldsymbol{\gamma}\right) p d f\left(\sigma_{i}^{2} \mid \boldsymbol{\gamma}\right) p d f(\boldsymbol{\gamma})
$$

Therefore, equation (5) can be rewritten as

$$
p d f\left(\boldsymbol{\beta}_{\boldsymbol{\gamma}}^{i}, \sigma_{i}^{2}, \boldsymbol{\gamma} \mid \mathbf{r}^{i}\right) \propto p d f\left(\mathbf{r}^{i} \mid \boldsymbol{\beta}_{\gamma}^{i}, \sigma_{i}^{2}, \boldsymbol{\gamma}\right) p d f\left(\boldsymbol{\beta}_{\boldsymbol{\gamma}}^{i} \mid \sigma_{i}^{2}, \boldsymbol{\gamma}\right) p d f\left(\sigma_{i}^{2} \mid \boldsymbol{\gamma}\right) p d f(\boldsymbol{\gamma})
$$

A structure such as (5) and (6) is called a hierarchical Bayes model.

Now make the following assumptions for the hierachical Bayes model. Firstly, the conditional $p d f$ of $\mathbf{r}$ for given parameters, $p d f\left(\mathbf{r} \mid \boldsymbol{\beta}_{\gamma}, \boldsymbol{\Sigma}, \boldsymbol{\gamma}\right)$, is assumed to have the following normal distribution,

$$
\operatorname{pdf}\left(\mathbf{r}^{i} \mid \boldsymbol{\beta}_{\gamma}^{i}, \sigma_{i}^{2}, \boldsymbol{\gamma}\right) \sim N\left(\mathbf{X}_{\gamma} \boldsymbol{\beta}_{\gamma}^{i}, \sigma_{i}^{2} \mathbf{I}_{n}\right) .
$$

For the priors, the following assumptions are used; these are the same as used in Smith and Kohn (1998).

1) In the following analysis, two different priors for $p d f\left(\boldsymbol{\beta}_{\gamma}^{i} \mid \sigma_{i}^{2}, \boldsymbol{\gamma}\right)$ are considered; the first prior is

$$
p d f\left(\boldsymbol{\beta}_{\gamma}^{i} \mid \sigma_{i}^{2}, \boldsymbol{\gamma}\right) \sim N\left(0, c \sigma_{i}^{2}\left(\mathbf{X}_{\gamma}^{\prime} \mathbf{X}_{\gamma}\right)^{-\mathbf{1}}\right)
$$

which is the same as that used in Smith and Kohn (1996), where they allow $c$ to take values in the range $10 \leq c \leq 1000$. The second prior is, by setting $p d f\left(\boldsymbol{\beta}_{\gamma}^{i} \mid \sigma_{i}^{2}, \boldsymbol{\gamma}\right) \propto p d f\left(\mathbf{r}^{i} \mid \boldsymbol{\beta}_{\gamma}^{i}, \sigma_{i}^{2}, \boldsymbol{\gamma}\right)^{1 / T}$ as in O'Hagan (1995), so that

$$
p d f\left(\boldsymbol{\beta}_{\gamma}^{i} \mid \sigma_{i}^{2}, \boldsymbol{\gamma}\right) \sim N\left(\left(\mathbf{X}_{\gamma}^{\prime} \mathbf{X}_{\gamma}\right)^{-1} \mathbf{X}_{\gamma}^{\prime} \mathbf{r}^{i}, T \sigma_{i}^{2}\left(\mathbf{X}_{\gamma}^{\prime} \mathbf{X}_{\gamma}\right)^{-\mathbf{1}}\right),
$$

where $T$ is the number of observations. The maximum likelihood estimator of $\boldsymbol{\beta}_{\gamma}^{i}$ is $\left(\mathbf{X}_{\gamma}^{\prime} \mathbf{X}_{\gamma}\right)^{-1} \mathbf{X}_{\gamma}^{\prime} \mathbf{r}^{i}$ and its variance is $\sigma_{i}^{2}\left(\mathbf{X}_{\gamma}^{\prime} \mathbf{X}_{\gamma}\right)^{-\mathbf{1}}$. The variances of these two priors are larger than that of the likelihood estimator because $c$ and $T$ are larger than 1 and thus the prior is less informative about $\boldsymbol{\beta}_{\gamma}^{i}$ than the likelihood.

2) The prior for $\sigma_{i}^{2}$ is the commonly used noninformative prior discussed in Geisser (1965). Under the assumption that the prior for $\sigma_{i}^{2}$ is taken as independent of $\boldsymbol{\gamma}$, that is, $p d f\left(\sigma_{i}^{2} \mid \boldsymbol{\gamma}\right)=p d f\left(\sigma_{i}^{2}\right)$, then

$$
p d f\left(\sigma_{i}^{2} \mid \gamma\right) \propto \frac{1}{\sigma_{i}^{2}} .
$$

3) Finally, assume that $p d f(\boldsymbol{\gamma})$ are independent of one another and set

$$
p d f\left(\gamma_{n}=1\right)=1 / 2 \quad \forall n .
$$


The above assumptions on priors imply that

$$
p d f\left(\boldsymbol{\beta}_{\gamma}^{i}, \boldsymbol{\beta}_{\gamma}^{j} \mid \boldsymbol{\Sigma}, \boldsymbol{\gamma}\right)=p d f\left(\boldsymbol{\beta}_{\gamma}^{i} \mid \boldsymbol{\Sigma}, \boldsymbol{\gamma}\right) p d f\left(\boldsymbol{\beta}_{\gamma}^{j} \mid \boldsymbol{\Sigma}, \boldsymbol{\gamma}\right), i \neq j
$$

where $\boldsymbol{\beta}_{\gamma}^{i}$ and $\boldsymbol{\beta}_{\gamma}^{j}$ are elements in the vector $\widetilde{\boldsymbol{\beta}}_{\boldsymbol{\gamma}}$ (see equation (3)) so that equation (12) demonstrates that the elements of $\widetilde{\boldsymbol{\beta}}_{\gamma}$ are conditionally independent. It also follows from the above that for any two asset returns vectors, $\mathbf{r}^{i}$ and $\mathbf{r}^{j}$,

$$
p d f\left(\mathbf{r}^{i}, \mathbf{r}^{j} \mid \widetilde{\boldsymbol{\beta}}_{\boldsymbol{\gamma}}, \boldsymbol{\Sigma}, \boldsymbol{\gamma}\right)=p d f\left(\mathbf{r}^{i} \mid \widetilde{\boldsymbol{\beta}}_{\boldsymbol{\gamma}}, \boldsymbol{\Sigma}, \boldsymbol{\gamma}\right) p d f\left(\mathbf{r}^{j} \mid \widetilde{\boldsymbol{\beta}}_{\gamma}, \boldsymbol{\Sigma}, \boldsymbol{\gamma}\right), i \neq j
$$

The task is now to compute the posterior probability of $\boldsymbol{\gamma}$, that is, $p d f\left(\gamma \mid \mathbf{r}^{i}\right)$. The posterior probability of $\boldsymbol{\gamma}$ is obtained by integrating the posterior joint density function $p d f\left(\boldsymbol{\beta}_{\boldsymbol{\gamma}}^{i}, \sigma_{i}^{2}, \boldsymbol{\gamma} \mid \mathbf{r}^{i}\right)$ with respect to $\boldsymbol{\beta}_{\boldsymbol{\gamma}}^{i}$ and $\sigma_{i}^{2}$,

$$
p d f\left(\boldsymbol{\gamma} \mid \mathbf{r}^{i}\right)=\int_{\sigma_{i}^{2}} \int_{\boldsymbol{\beta}_{\gamma}^{i}} p d f\left(\boldsymbol{\beta}_{\gamma}^{i}, \sigma_{i}^{2}, \boldsymbol{\gamma} \mid \mathbf{r}^{i}\right) d \boldsymbol{\beta}_{\gamma}^{i} d \sigma_{i}^{2}
$$

Substituting equation (6) into equation (14), produces

$$
p d f\left(\boldsymbol{\gamma} \mid \mathbf{r}^{i}\right) \propto p d f(\boldsymbol{\gamma}) \int_{\sigma_{i}^{2}} \int_{\boldsymbol{\beta}_{\gamma}^{i}} p d f\left(\mathbf{r}^{i} \mid \boldsymbol{\beta}_{\gamma}^{i}, \sigma_{i}^{2}, \boldsymbol{\gamma}\right) p d f\left(\boldsymbol{\beta}_{\gamma}^{i} \mid \sigma_{i}^{2}, \boldsymbol{\gamma}\right) p d f\left(\sigma_{i}^{2} \mid \boldsymbol{\gamma}\right) d \boldsymbol{\beta}_{\gamma}^{i} d \sigma_{i}^{2}
$$

Firstly, consider the first prior for $p d f\left(\boldsymbol{\beta}_{\gamma}^{i} \mid \sigma_{i}^{2}, \boldsymbol{\gamma}\right)$ as in equation (8). Note that $p d f\left(\mathbf{r}^{i} \mid \boldsymbol{\beta}_{\gamma}^{i}, \sigma_{i}^{2}, \boldsymbol{\gamma}\right)$ is the conventional likelihood function as in (7) and the prior pdf's for $p d f\left(\boldsymbol{\beta}_{\gamma}^{i} \mid \sigma_{i}^{2}, \boldsymbol{\gamma}\right)$ and $p d f\left(\sigma_{i}^{2} \mid \boldsymbol{\gamma}\right)$ are given in equations (8) and (10), respectively. The pdf's allow use of the result of equation (2.3) of Smith and Kohn (1996);

$$
\begin{aligned}
p d f\left(\mathbf{r}^{i} \mid \boldsymbol{\gamma}\right) & \propto \int_{\sigma_{i}^{2}} \int_{\boldsymbol{\beta}_{\gamma^{i}}} p d f\left(\mathbf{r}^{i} \mid \boldsymbol{\beta}_{\boldsymbol{\gamma}}^{i}, \sigma_{i}^{2}, \boldsymbol{\gamma}\right) p d f\left(\boldsymbol{\beta}_{\boldsymbol{\gamma}}^{i} \mid \sigma_{i}^{2}, \boldsymbol{\gamma}\right) p d f\left(\sigma_{i}^{2} \mid \boldsymbol{\gamma}\right) d \boldsymbol{\beta}_{\boldsymbol{\gamma}}^{i} d \sigma_{i}^{2} \\
& =(1+c)^{-q_{\gamma} / 2} S^{i}(\boldsymbol{\gamma})^{-T / 2}
\end{aligned}
$$

where $c$ is a fixed positive constant and $S^{i}(\boldsymbol{\gamma})=\mathbf{r}^{i \prime}\left(\mathbf{I}_{T}-\frac{c}{1+c} \mathbf{X}_{\boldsymbol{\gamma}}\left(\mathbf{X}_{\gamma}^{\prime} \mathbf{X}_{\gamma}\right)^{-1} \mathbf{X}_{\gamma}^{\prime}\right) \mathbf{r}^{i}$. If it is assumed that $p\left(\gamma_{n}=1\right)=\pi_{n}$ for $n=1, \ldots, q_{\gamma}$, then for $\boldsymbol{\gamma}^{*}$ a vector of particular values,

$$
p\left(\boldsymbol{\gamma}^{*}\right)=p\left(\boldsymbol{\gamma}=\boldsymbol{\gamma}^{*}\right)=\prod_{n=1}^{q_{\gamma}}\left(\pi_{n}\right)^{\gamma_{n}^{*}}\left(1-\pi_{n}\right)^{1-\gamma_{n}^{*}}
$$

In the $m$ regression equation system with the same independent variables and a diagonal variance-covariance matrix as in equation (3), the posterior probability of $\gamma$ is

$$
p(\boldsymbol{\gamma} \mid \mathbf{r})=\frac{p(\mathbf{r} \mid \boldsymbol{\gamma}) p(\boldsymbol{\gamma})}{p(\mathbf{r})}
$$




$$
\begin{aligned}
& =\prod_{i=1}^{m} \frac{p\left(\mathbf{r}^{i} \mid \boldsymbol{\gamma}\right) p(\boldsymbol{\gamma})}{p(\mathbf{r})} \\
& \propto \prod_{i=1}^{m} p\left(\mathbf{r}^{i} \mid \boldsymbol{\gamma}\right) p(\boldsymbol{\gamma}) \\
& \propto p(\boldsymbol{\gamma}) \prod_{i=1}^{m}(1+c)^{-q_{\gamma} / 2} S^{i}(\boldsymbol{\gamma})^{-T / 2}
\end{aligned}
$$

On the other hand,

$$
\begin{aligned}
p(\mathbf{r}) & =\int p(\mathbf{r} \mid \boldsymbol{\gamma}) p(\boldsymbol{\gamma}) d \boldsymbol{\gamma} \\
& =\sum_{\boldsymbol{\gamma} \in \mathbf{S}} p(\boldsymbol{\gamma}) \prod_{i=1}^{m}(1+c)^{-q_{\gamma} / 2} S_{i}(\boldsymbol{\gamma})^{-T / 2}
\end{aligned}
$$

Therefore, with equations (18) and (19),

$$
\begin{aligned}
p\left(\boldsymbol{\gamma}=\boldsymbol{\gamma}^{*} \mid \mathbf{r}\right) & =\frac{p\left(\mathbf{r} \mid \boldsymbol{\gamma}^{*}\right) p\left(\boldsymbol{\gamma}^{*}\right)}{p(\mathbf{r})} \\
& \propto \frac{p\left(\boldsymbol{\gamma}^{*}\right) \prod_{i=1}^{m}(1+c)^{-q_{\gamma^{*}} / 2} S^{i}\left(\boldsymbol{\gamma}^{*}\right)^{-T / 2}}{\sum_{\boldsymbol{\gamma} \in \mathbf{S}} p(\boldsymbol{\gamma}) \prod_{i=1}^{m}(1+c)^{-q_{\gamma} / 2} S^{i}(\boldsymbol{\gamma})^{-T / 2}}
\end{aligned}
$$

where $\mathbf{S}$ is the set of all possible $\boldsymbol{\gamma}^{\prime} s$. Note that if $\pi_{n}=\frac{1}{2}, n=1, . ., q_{\gamma}$, then $p\left(\boldsymbol{\gamma}=\boldsymbol{\gamma}^{*}\right)=\left(\frac{1}{2}\right)^{q_{\gamma}}$. In this case, $p(\boldsymbol{\gamma})$ and $p\left(\boldsymbol{\gamma}^{*}\right)$ cancel out and the formula simplifies to

$$
p\left(\boldsymbol{\gamma}=\boldsymbol{\gamma}^{*} \mid \mathbf{r}\right)=\frac{\prod_{i=1}^{m}(1+c)^{-q_{\gamma^{*}}^{i} / 2} S^{i}\left(\boldsymbol{\gamma}^{*}\right)^{-T / 2}}{\sum_{\boldsymbol{\gamma} \in \mathbf{S}} \prod_{i=1}^{m}(1+c)^{-q_{\gamma}^{i} / 2} S^{i}(\boldsymbol{\gamma})^{-T / 2}}
$$

Secondly, if it is assumed that $p d f\left(\boldsymbol{\beta}_{\gamma}^{i} \mid \sigma_{i}^{2}, \boldsymbol{\gamma}\right) \sim N\left(\left(\mathbf{X}_{\gamma}^{\prime} \mathbf{X}_{\gamma}\right)^{-\mathbf{1}} \mathbf{X}_{\gamma}^{\prime} \mathbf{r}^{i}, T \sigma_{i}^{2}\left(\mathbf{X}_{\gamma}^{\prime} \mathbf{X}_{\gamma}\right)^{-\mathbf{1}}\right)$, then the result is as before, except that instead of $(1+c)^{-q_{\gamma} / 2},(1+T)^{-q_{\gamma} / 2}$ is used. This may be better as the auxiliary constant $c$ need not be specified.

\section{Empirical Tests}

\subsection{Equity Returns}

The Morgan Stanley Capital International (MSCI) universe is used as the data set. Firstly, the 1523 equities available in the MSCI universe are taken and then equities selected which are available over the sample period, that is, from October 1988 to September 1998. The number of equities available during the period is 1154 . Therefore, a total number of 120 monthly returns from October 1988 to September 
1998 is used for each equity. Using the notation of the previous section, $m=1154$ and $T=120$.

The MSCI universe has information on countries (20 countries) and sectors (9 sectors) for each equity. The strategy is to take out the country and sector effects prior to analysing style. However, in many cases, weights on sector - country grids are very small and there are very large differences in the weights. In addition, a large number of countries and sectors $(20 \times 9$ grids $)$ can make the calculation more complicated without giving meaningful results. In this study, the number of sectors and countries is reduced by pooling. Twenty countries are pooled into 9 geographical groups as follows: Canada, France, Germany, Japan, UK, US, Other Europe (Belgium, Denmark, Finland, Ireland, Italy, Netherlands, Norway, Spain, Sweden, and Swizerland), Australasia (Australia and New Zealand), and Asia (Hong Kong, Malaysia, and Singapore). Sectors are also re-grouped as Basic Industries, Capital Goods, Consumer Goods, Energy, Financials, and Others (Resources, Transport, Utilities and Other sectors). These produce 6 new sectors. With these pooling procedures, there are $54(9 \times 6)$ country-sector grids.

Firstly, cross-sectional weights on each equity at time $t$ are calculated as follows

$$
w_{k, l, i, t}=\frac{s_{k, l, i, t}}{\sum_{i=1}^{N^{k l}} s_{k, l, i, t}}
$$

where $k$ and $l$ represent the $k$ th country and the $l$ th sector, respectively, $N^{k l}$ is the number of equities in the $(k-l)$ th country-sector grid, and $s_{k, l, i, t}$ represents market value (in US dollar terms) of equity $i$ at time $t$. Note that $\sum_{i=1}^{N^{k l}} w_{k, l, i, t}=1$ for all country-sector grids. Then, the value weighted excess return of an equity that belongs to the $k$ th country and $l$ th sector at time $t, R_{k, l, i, t}$, is

$$
R_{k, l, i, t}=r_{k, l, i, t}-\sum_{i=1}^{N^{k l}} w_{k, l, i, t} r_{k, l, i, t} .
$$

Note that for the case of the equally weighted excess return of an equity that belongs to $k$ th country and $l$ th sector at time $t$, the study uses $w_{k, l, i, t}=\frac{1}{N^{k l}}$.

Table 1 reports some basic information on the equities used in this study. Note that the returns are averaged over the sample period, i.e., $\sum_{t=1}^{T} \bar{r}_{k, l, t}$. Panel A of table 1 shows that there are 295 Japanese equities which is $25.6 \%$ of all equities by number. However, they cover $42.5 \%$ in value, see panel B. There are 265 US equities, whose value is $25.3 \%$. Therefore, the data include more Japanese equities, that are also large in value on average. Note that equities of the other countries are relatively small. Panel B shows that Japanese equities in the finance sector are more than twice as large as the US equities in the same sector. Also note that the Japanese Capital Goods sector is the largest sector in both number and value.

Panel $\mathrm{C}$ shows equally weighted and value weighted returns on a country/sector grid. The weighted average returns of Japanese equities are very small, i.e., $0.1 \%$ 
a month, mainly due to the sluggish Japanese economy during the sample period. Also, note that the equities of Canada and Australasia have relatively low returns. All the other countries' weighted average returns are around 1.3 to $1.6 \%$ a month. Panel D shows a similar pattern in equally weighted returns; equally weighted returns on Japanese equities are negative, $-0.03 \%$ a month, while those of other countries are broadly similar, i.e., 0.7 to $1.4 \%$ a month.

The number and value of equities in Capital Goods and Consumer Goods are large, more than half of the number and value of total equities. During the sample period, the Consumer Goods sector showed the highest weighted return, 1.24\% a month (see panel C). The Basic Industries weighted return was $-0.02 \%$. However, the difference between sectors is relatively smaller than that between countries.

There is a big difference in both the number and value of equities among countries and sectors. For example, the value of the Capital Goods sector is more than ten times larger than that of the basic indutries sector. A similar phenomenon can be found in country portfolios. This is the main reason why value weighted returns are used in this study. However, the Bayesian variable selection method described has been applied in the previous section to both equally weighted returns and value weighted returns for comparison purposes.

\subsection{Factor Mimicking Portfolios (FMPs)}

In linear factor models, one needs either the factors themselves, or their equilibrium risk premiums or a portfolio that mimics one or the other. Since the true factors are typically unobservable, only the last of these three cases is discussed. The decision to concentrate on building models using factor mimicking portfolios as regressors is in line with the more sophisticated practitioner models that are based on these procedures.

For the purposes of this paper, a factor-mimicking portfolio is a portfolio of assets whose returns are designed to be highly correlated with the (unobservable) factor values. Portfolios constructed from eigenvectors in principal component analysis are examples of factor mimicking portfolios. Factor mimicking portfolios are a useful and increasingly common tool in building linear factor models; they often take the form of a hedge portfolio. Even in cases when the factor is directly observable or prespecified, it is often convenient to use factor mimicking portfolios. For example, if a particular factor does not correspond to a set of traded positions, it may be hard to argue that a pricing theory applies to it, although (by construction) it would apply to a factor mimicking portfolio. For a more detailed discussion on the general theory of factor mimicking portfolios, see Huberman et al. (1987).

The returns to the factor-mimicking portfolios mimic the factor values in a certain sense. The relationship between the factor values and the corresponding factor premiums arises from theories such as Arbitrage Pricing Theory, which essentially links, in a no-arbitrage world, the exposure of the stocks to the factors, and the risk 
premiums associated with the factors to the overall risk premium of the asset.

Suppose stock returns $r_{i, t}$ can be modelled as

$$
r_{i, t}=\alpha+\sum_{f=1}^{m} \beta_{i, f} \phi_{f, t}+\varepsilon_{i, t}
$$

where $\beta_{i, f}$ is some measure of the exposure of stock $i$ to factor $f, \phi_{f, t}$ is some measure of the value of factor $f$ at time $t$, and $\varepsilon_{i, t}$ is noise. For each factor $f$, the universe is ranked by an attribute of $f$. For instance, $f$ might be the Return on Equity factor and the universe of stocks would be ranked by their Return on Equity attribute data. For the attributes used in this study, see the Appendix. Then an equally weighted portfolio is formed that is long the top $n$-tile ranked by the $f$ attribute, and short the bottom $n$-tile, ranked by the $f$ attribute. The resulting hedge portfolio is the factor mimicking portfolio of factor $f$. The order of the $n$-tile should typically be small. Thus, the use of quartiles $(n=4)$ or thirds $(n=3)$ is probably more appropriate than the use of, for example, deciles $(n=10)$, because of the greater diversification produced. In this particular model thirds have been used.

Important issues arise as to whether it is sensible to rank stocks by accounting attribute across countries and accounting regime. Initially, accounting regime differences are ignored; however, the second approach is to normalise the accounting data by country so that each "country" has an attribute with mean zero and variance one.

The above procedure can be seen as a natural way to make the factor mimicking portfolios approximately uncorrelated. If the true factors are uncorrelated, then sorting by the attributes and constructing long and short positions relative to factor 1, say, should produce a portfolio with little to no systematic exposure to factor 2. Actually, the attributes themselves may be strongly correlated and, as a consequence, fully uncorrelated portfolios cannot be expected. However, it is considered that this procedure is preferable to using factor analysis or principal components, since then one usually loses any understanding of what the factors signify.

The same data is used as was used in the previous subsection; 1523 equities in the MSCI universe from October 1988 to September 1998. First, the values of attributes for each equity as defined in the Appendix are calculated. The four styles used in this study are value (VL), growth (GR), total debt/book value ratio (DE), and size (SZ). Then the equities are ranked to the values of attributes in descending order. The four FMP values are returns of a portfolio which "longs" the top one-third and "shorts" the bottom one-third of the ranked equities. The FMP calculated for the four styles are FVL (value), FGR (growth), FDE (total debt/book value ratio), and FSZ (size). Note that the returns of the FMPs are calculated each month. Thus, the number of equities used for the calculation of FMPs changes over time (but the maximum number is 1523), while the number of equities available used in the previous subsection is fixed, i.e., 1154 throughout the sample period. 
Table 2 reports some properties of the FMPs for two cases; 1) when accounting regime differences are not considered (call the FMPs calculated in this way "nonstandardised FMP", see panel A), and 2) when accounting regime differences are considered (call the FMPs calculated in this way "standardised FMP", panel B). Note that FSZ is not changed by the accounting difference since there is no accounting attribute to be used for the calculation of FSZ. However, for the other FMPs, the two cases give different properties to the FMPs.

The standard errors of the non-standardised FVL and FGR are larger than those of the standardised FMPs. In addition, note that the non-standardised FMPs tend to have larger skewness and kurtosis. This is because the equities of a country may have relatively very high (or low) values in a style if the country's accounting attributes are not considered. For example, equities in emerging markets tend to be more geared than those in mature markets since there is more growth potential in emerging markets. In this case, the FGR may be highly associated with Asian equities, which usually show high growth ratios and thus are likely to belong to the top third in growth. Therefore, non-standardised accounting information across countries may systematically bias FMPs. This also explains why the correlation coefficients of the non-standardised FMPs are higher than those of the standardised FMPs, as can be seen in panels A2 and B2. By standardising accounting attributes, one country's dominance in the calculation of FMPs can be removed. This procedrue is also consistent with the assumption that factors are uncorrelated in the standard linear factor model. In the following subsection, both the non-standardised FMPs and the standardised FMPs are used and the results compared.

\subsection{Posterior Probability of $\gamma$}

This section calculates the posterior probability of $\gamma$, that is, $p d f(\gamma \mid \mathbf{r})$ in equation (21). Note that it uses a constant and the four FMPs as independent variables. Therefore, the possible number of the combinations of independent variables is sixteen. Some of the independent variable sets, except the constant, for example, are "FVL", "FGR", "FVL+FGR", "FGR+FDE+FSZ", or "NONE", see table 3. Therefore, the posterior probability of $\boldsymbol{\gamma}$ is a $(16 \times 1)$ vector, i.e., $\boldsymbol{\gamma}^{*}$ takes 16 values.

During the calculation with equation (21), the authors faced numerical difficulties in obtaining a sensible number for the posterior probability of $\gamma$. This is because the product of small posterior probabilities (the number is 1154) in each equity becomes very close to zero, while the product of large posterior probabilities in each equity becomes very large. Attempts were made to scale the values in sensible ways, but typically, the posterior probability of "NONE" becomes one and all the other posterior probability turn out to be zero. Accordingly, the problem was respecified by letting $\gamma$ be the $(16 \times 1)$ vector of specifications for asset $i$. Thus the calculations are carrued out for each equity rather than for all equities. Thus, the posterior 
probability vector for equity $i, \gamma^{i}$, is

$$
p\left(\boldsymbol{\gamma}^{i}=\boldsymbol{\gamma}^{*} \mid \mathbf{r}^{i}\right)=\frac{(1+c)^{-q_{\gamma^{*}}^{i} / 2} S^{i}\left(\boldsymbol{\gamma}^{*}\right)^{-T / 2}}{\sum_{\boldsymbol{\gamma}^{i} \in \mathbf{S}}(1+c)^{-q_{\gamma}^{i} / 2} S^{i}\left(\boldsymbol{\gamma}^{i}\right)^{-T / 2}}
$$

where all notation is the same as in equation (22). The numbers shown in tables 3 , 4 , and 5 are the averaged posterior probabilities of countries, sectors, and countrysector grids. Such a procedure helps circumvent the numeric problems associated with a system $\gamma$, as opposed to the equity-specific $\gamma^{i}$ 's that were calculated.

First, the results of the non-standardised FMPs are reported and then the results of the standardised FMPs. The results on the equally weighted returns follow next. Table 3 reports the results of the non-standardised FMPs. For the non-standardised FMPs evidence was not found of global style effects for all countries and sectors; see panels A and B of table 3. Panel A shows that styles cannot explain countries since "NONE" has the highest posterior probability for all 9 countries. Indeed it is usually at least four times as high as the next highest probability. Panel B reports similar results. This suggests that the methodology effectively removes the country/sector effects.

Moving down a level to the individual country/sector combinations in panel $\mathrm{C}$ of table 3 , there seems to be weak evidence of individual combinations being sensitive to style; some configurations are listed. The financial sectors in Germany may be explained by a style, that is, growth. Two sectors are explained in Japan by growth and the combination of growth and debt. In Asian Countries, two sectors (Basic Industries and Energy) are explained by value and growth, respectively. On the other hand, Canada, France, UK, US, Other European Countries, and Australasia are unaffected by any style variable in any sector.

Summarising the results, this study did not find strong evidence of the role of style, but the possibility cannot be ignored that some results may come from global accounting differences, especially for Asian definitions of book value and debt.

The posterior probabilities are recalculated using standardised FMP's to allow for the different accounting regimes across countries. Table 4 shows that global style effects are not found in all countries and sectors; see panels A and B of table 4. All posterior probabilities are similar to those reported in panels $\mathrm{A}$ and $\mathrm{B}$ of table 3. Panel $\mathrm{C}$ of table 4 also suggests that the standardised FMPs only have limited explanatory power in the individual country/sector combinations.

The selection of FMPs and their posterior probabilities in the individual country/sector combinations are different from those reported in table 3. For example, growth explains Japanese equities better than the other combination of FMPs with non-standardised FMPs. However, with standardised FMPs, size is the appropriate style for Japanese equities. Similar differences can be found in other countries.

The calculations are reworked by computing excess return, with respect to equally, rather than capital, weighted averages. This should reduce the importance of Japan relative to the rest as we have already seen that, globally, firm size is larger in Japan 
than for the rest of the world. These results are presented in table 5. These are not discussed at length, except to note that the results are very similar to those in table 4; there is little evidence for the importance of global styles.

We conclude that global style is not a risk factor in explaining global stock returns.

\subsection{Time-varying Properties of Posterior Probability of $\gamma$}

Tables 3 to 5 report the posterior probabilities of $\gamma$ for each country/sector grid over the entire sample period, i.e., October 1988 to September 1998. The selections of FMPs are assumed to be time-invariant in those tables. As in most economic and financial variables, we do not exclude time-varying properties of the posterior probabilities of $\gamma$. In this subsection, posterior probabilities are calculated using rolling windows and the time-varying properties of the posterior probabilities are investigated.

The study uses 60 monthly equity returns and FMP returns to calculate the posterior probabilities. The first sample period covers October 1988 to September 1993. The second sample period covers November 1988 to October 1993, and so on. Standardised value-weighted returns are used so that the results in this subsection can be compared with those in table 4, which is obtained with the entire sample. Thus the constant $\gamma$ can be compared with time-varying $\gamma_{t}$.

In the first sample period, prior probabilities of $\gamma$ were set to one-half, but from the second sample period the previous period's posterior probabilities were used as prior probabilities for the calculation of current posterior probabilities. Therefore, the posterior probabilities are calculated using the following equation;

$$
p\left(\boldsymbol{\gamma}_{t}^{i}=\boldsymbol{\gamma}^{*} \mid \mathbf{r}_{t}^{i}\right)=\frac{p\left(\boldsymbol{\gamma}_{t-1}^{i}=\boldsymbol{\gamma}^{*} \mid \mathbf{r}_{t-1}^{i}\right)(1+c)^{-q_{\gamma^{*}}^{i} / 2} S_{t}^{i}\left(\boldsymbol{\gamma}^{*}\right)^{-T / 2}}{\sum_{\boldsymbol{\gamma} \in \mathbf{S}} p\left(\boldsymbol{\gamma}_{t-1}^{i} \mid \mathbf{r}_{t-1}^{i}\right)(1+c)^{-q_{\gamma}^{i} / 2} S_{t}^{i}(\boldsymbol{\gamma})^{-T / 2}}
$$

where $S_{t}^{i}(\boldsymbol{\gamma})=\mathbf{r}_{t}^{i \prime}\left(\mathbf{I}_{T}-\frac{c}{1+c} \mathbf{X}_{t, \boldsymbol{\gamma}}\left(\mathbf{X}_{t, \boldsymbol{\gamma}}^{\prime} \mathbf{X}_{t, \boldsymbol{\gamma}}\right)^{-1} \mathbf{X}_{t, \boldsymbol{\gamma}}^{\prime}\right) \mathbf{r}_{t}^{i}, c=60, T=60$, and $\mathbf{r}_{t}^{i}$ and $\mathbf{X}_{t, \boldsymbol{\gamma}}$ are vectors of 60 monthly returns of equity $i$ and the selected combinations of FMPs up to time $t$, respectively. With the total number of 120 monthly observations, 61 posterior probabilities were calculated for each equity.

A problem in using the previous period's posterior probabilities as prior probabilities occurs when any of the previous period's posterior probabilities is zero or close to zero. In this case, equation (23) shows that all current and future posterior probability with the zero prior probability becomes zero. To avoid this, the prior probability (previous posterior probability) was scaled as follows;

$$
p^{*}\left(\boldsymbol{\gamma}_{t-1}^{i}=\boldsymbol{\gamma}^{*} \mid \mathbf{r}_{t-1}^{i}\right)=\frac{\operatorname{MIN}\left(\operatorname{MAX}\left(p\left(\boldsymbol{\gamma}_{t-1}^{i}=\boldsymbol{\gamma}^{*} \mid \mathbf{r}_{t-1}^{i}\right), 0.02\right), 0.98\right)}{\sum_{\boldsymbol{\gamma} \in \mathbf{S}}\left[\operatorname{MIN}\left(\operatorname{MAX}\left(p\left(\boldsymbol{\gamma}_{t-1}^{i}=\boldsymbol{\gamma}^{*} \mid \mathbf{r}_{t-1}^{i}\right), 0.02\right), 0.98\right)\right]}
$$

That is, prior probabilities were set to $2 \%$ when they were less than $2 \%$, and to $98 \%$ when they were larger than $98 \%$, and then the prior probabilities were recalculated 
using equation (24). For example, when one previous posterior probability was $100 \%$ and all the others (15 combinations of FMPs in this study) were $0 \%$, the recalculated prior probabilities were $76.56 \%$ and $1.56 \%$, respectively.

Posterior probabilties were calculated for each of the 1154 equities in the sample, although they are not reported. Figure 1 reports only one sector in each country. Note that the posterior probabilities are averaged cross-sectionally across equities and combinations of FMPs whose posterior probabilities are close to zero throughout time were not reported.

The figure shows there are several combinations of FMPs which explain country/sector through time. Thus, even though posterior probabilities are changing throughout time, the number of the combinations of FMPs themselves are less than half of the original sixteen combinations. As already seen in the previous section, "NONE" dominates all the other combinations of styles throughout time, except for Japanese Capital Goods, where size and recent value perform well relative to other country/sector grids.

In most cases the posterior probability of 'none' starts around $40 \%$ and then becomes larger as time passes. This is because the first posterior probabilities are calculated by setting all prior probilities to one-half, but the other posterior probabilities after the first ones are obtained by using the previous period's posterior probabilities as prior probabilities.

Note that Capital Goods for Germany, Japan, and UK are not explained with the same combinations of FMPs. When "NONE" is excluded, Japanese Capital Goods are explained by size, among others, but UK Capital Goods are explained by growth. Although the other country/sector grids are not reported, it is found that growth and size perform well, except for "NONE" in UK and Japan, respectively. The selection of FMPs does depend on countries, even though equities are in the same sector.

One property which is represented in figure 1 is that the posterior probabilities are time-varying rather than constant throughout time, but they do not show any dramatic changes to time.

\section{Conclusions}

In this paper Bayesian variable selection methods have been used to identify style in a global linear factor model. It was found that equities are not well explained by any combination of styles. These results suggest that global style is not an appropriate choice of factor for modelling risk.

If styles cannot explain risk, they may still be useful in forecasting returns, i.e., in stock selection. The view has been expressed that styles may reflect anomolous behaviour and may result from the irrational behaviour of the investor. The results of this study are not in conflict with this view. 


\section{References}

Arshanapalli, B., T. D. Coggin, and J. Doukas, 1998, Multifactor Asset Pricing Analysis of International Value Investment Strategies, Journal of Portfolio Management.

Capaul, C., I. Rowley, and W. F. Sharpe, 1993, International Value and Growth Stock Returns, Financial Analysts Journal, January-February, 27-36.

Fama, E. F., and K. R. French, 1998, Value versus Growth: The International Evidence, Journal of Finance, 1975-1999.

Geisser, S., 1965, A Bayes Approach for Combining Correlated Estimates, Journal of American Statistical Association 60, 602-607.

Hamilton, J. D., 1990, Analysis of Time Series Subject to Changes in Regime, Journal of Econometrics 45, 39-70.

Heston, S. L. and Rouwenhorst K. G, 1995, Industry and Country Effects in International Stock Returns, Journal of Portfolio Management 21, 53-58.

Kuo, G. W. and S. E. Satchell, 1998, Global Equity Styles and Industry Effects: Portfolio Construction via Dummy Variables, DAE Working Paper \#9807, Department of Applied Economics, Cambridge University.

O'Hagan, A., 1995, Fractional Bayes Factors for Model Comparison, Journal of Royal Statistical Association, Series B, 57, 99-138.

Smith, M. and R. Kohn, 1996, Nonparametric Regression via Bayesian Variable Selection, Journal of Econometrics 75, 317-344.

Smith, M. and R. Kohn, 1998, Nonparametric Seemingly Unrelated Regression, mimeo, Australian Graduate School of Management, Sydney, Australia.

Huberman, G., A. Shmuel, and R. F. Stambaugh, 1987, 'Mimicking Portfolios and Exact Arbitrage Pricing, Journal of Finance 42, 1-10. 


\section{Appendix Definitions of Style Variables}

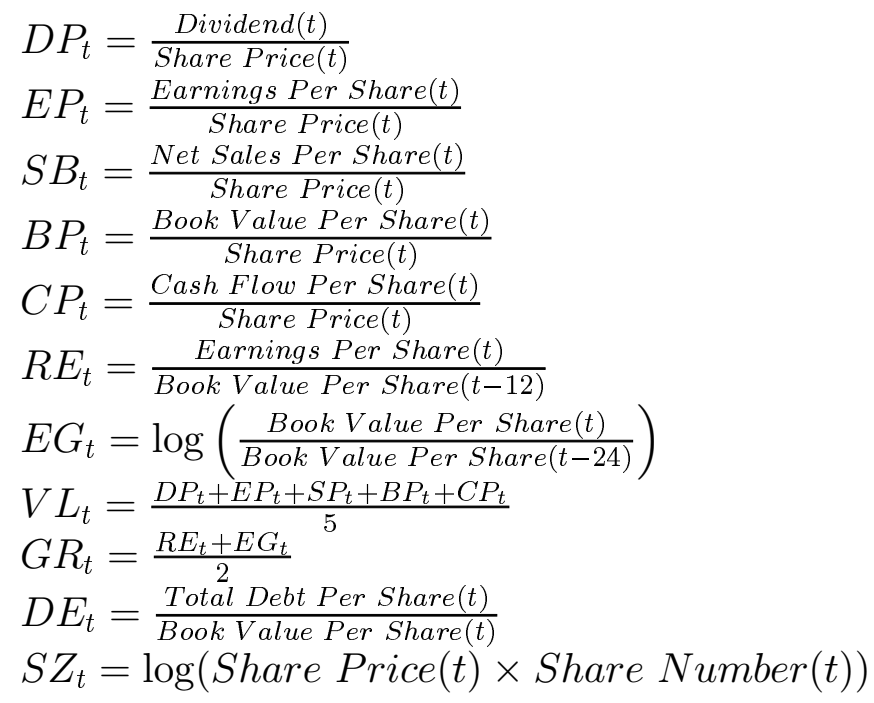


Table 1 Number of Equities and Weights on Countries and Sectors

A. Number of Equities on Country-Sector Grids

\begin{tabular}{|c|c|c|c|c|c|c|c|}
\hline Countries & $\begin{array}{c}\text { Basic } \\
\text { Industries }\end{array}$ & $\begin{array}{l}\text { Capital } \\
\text { Goods }\end{array}$ & $\begin{array}{c}\text { Consumer } \\
\text { Goods }\end{array}$ & Energy & Financials & Others & $\begin{array}{l}\text { Country } \\
\text { Total }\end{array}$ \\
\hline Canada & 5 & 7 & 11 & 13 & 7 & 15 & 58 \\
\hline France & 0 & 15 & 16 & 3 & 11 & 7 & 52 \\
\hline Germany & 2 & 25 & 8 & 0 & 10 & 6 & 51 \\
\hline Japan & 12 & 130 & 75 & 6 & 35 & 37 & 295 \\
\hline UK & 0 & 42 & 27 & 3 & 19 & 7 & 98 \\
\hline US & 10 & 76 & 71 & 14 & 40 & 54 & 265 \\
\hline $\begin{array}{c}\text { Other European } \\
\text { Countries }\end{array}$ & 9 & 62 & 40 & 4 & 33 & 32 & 180 \\
\hline Australasia & 3 & 8 & 10 & 2 & 10 & 20 & 53 \\
\hline Asian Countries & 3 & 22 & 19 & 2 & 28 & 28 & 102 \\
\hline Sector Total & 44 & 387 & 277 & 47 & 193 & 206 & 1,154 \\
\hline
\end{tabular}

B. Weights on Country-Sector Grids Averaged over October 1988 - September 1998

\begin{tabular}{|c|rrrrrr|r|}
\hline Countries & $\begin{array}{r}\text { Basic } \\
\text { Industries }\end{array}$ & $\begin{array}{l}\text { Capital } \\
\text { Goods }\end{array}$ & $\begin{array}{c}\text { Consumer } \\
\text { Goods }\end{array}$ & Energy & Financials & Others & $\begin{array}{c}\text { Country } \\
\text { Total }\end{array}$ \\
\hline Canada & $0.10 \%$ & $0.42 \%$ & $0.40 \%$ & $0.44 \%$ & $0.48 \%$ & $0.56 \%$ & $2.40 \%$ \\
France & - & $1.23 \%$ & $0.72 \%$ & $0.62 \%$ & $0.64 \%$ & $0.34 \%$ & $3.55 \%$ \\
Germany & $0.13 \%$ & $1.16 \%$ & $0.12 \%$ & - & $0.59 \%$ & $0.32 \%$ & $2.32 \%$ \\
Japan & $1.86 \%$ & $16.56 \%$ & $6.94 \%$ & $0.54 \%$ & $10.78 \%$ & $5.83 \%$ & $42.51 \%$ \\
UK & - & $3.07 \%$ & $3.98 \%$ & $0.91 \%$ & $1.90 \%$ & $0.62 \%$ & $10.49 \%$ \\
US & $0.64 \%$ & $6.52 \%$ & $8.40 \%$ & $2.12 \%$ & $4.16 \%$ & $3.48 \%$ & $25.31 \%$ \\
Other European & & & & & & & \\
Countries & $0.13 \%$ & $2.53 \%$ & $1.80 \%$ & $0.74 \%$ & $1.73 \%$ & $0.89 \%$ & $7.80 \%$ \\
Australasia & $0.19 \%$ & $0.25 \%$ & $0.36 \%$ & $0.05 \%$ & $0.64 \%$ & $0.99 \%$ & $2.48 \%$ \\
Asian Countries & $0.03 \%$ & $0.51 \%$ & $0.30 \%$ & $0.02 \%$ & $1.26 \%$ & $1.02 \%$ & $3.14 \%$ \\
\hline Sector Total & $3.07 \%$ & $32.25 \%$ & $23.02 \%$ & $5.44 \%$ & $22.17 \%$ & $14.05 \%$ & $100.00 \%$ \\
\hline
\end{tabular}


C. Value Weighted Returns on Country-Sector Grids Averaged over October 1988 - September 1998

\begin{tabular}{|c|c|c|c|c|c|c|c|}
\hline Countries & $\begin{array}{c}\text { Basic } \\
\text { Industries }\end{array}$ & $\begin{array}{l}\text { Capital } \\
\text { Goods }\end{array}$ & $\begin{array}{c}\text { Consumer } \\
\text { Goods }\end{array}$ & Energy & Financials & Others & $\begin{array}{c}\text { Country } \\
\text { Total }\end{array}$ \\
\hline Canada & 0.07 & 1.07 & 0.75 & 0.39 & 1.10 & 0.47 & 0.72 \\
\hline France & - & 1.12 & 1.69 & 1.98 & 1.19 & 1.43 & 1.43 \\
\hline Germany & 1.01 & 1.32 & 1.00 & - & 1.38 & 1.62 & 1.34 \\
\hline Japan & -0.52 & 0.32 & 0.42 & -0.32 & -0.23 & -0.07 & 0.10 \\
\hline UK & - & 1.16 & 1.60 & 1.45 & 1.50 & 0.83 & 1.40 \\
\hline US & 1.01 & 1.51 & 1.67 & 1.16 & 1.77 & 1.13 & 1.51 \\
\hline Other European & & & & & & & \\
\hline Countries & 0.76 & 1.23 & 1.54 & 1.29 & 1.19 & 1.61 & 1.33 \\
\hline Australasia & 0.08 & 0.40 & 0.90 & 0.88 & 0.99 & 0.79 & 0.77 \\
\hline Asian Countries & 0.69 & 1.69 & 1.26 & 0.60 & 1.67 & 1.56 & 1.58 \\
\hline Sector Total & -0.02 & 0.81 & 1.24 & 1.11 & 0.66 & 0.65 & 0.84 \\
\hline
\end{tabular}

D. Equally Weighted Returns on Country-Sector Grids Averaged over October 1988 - September 1998

\begin{tabular}{|c|rrrrrr|r|}
\hline Countries & $\begin{array}{c}\text { Basic } \\
\text { Industries }\end{array}$ & $\begin{array}{c}\text { Capital } \\
\text { Goods }\end{array}$ & $\begin{array}{c}\text { Consumer } \\
\text { Goods }\end{array}$ & Energy & Financials & Others & $\begin{array}{c}\text { Country } \\
\text { Total }\end{array}$ \\
\hline Canada & -0.07 & 0.79 & 0.67 & 1.22 & 1.33 & 0.30 & 0.73 \\
France & - & 1.11 & 1.40 & 1.68 & 0.84 & 1.10 & 1.17 \\
Germany & 0.91 & 0.91 & 0.81 & - & 1.30 & 1.29 & 1.01 \\
Japan & -0.41 & 0.11 & 0.03 & -0.43 & -0.23 & -0.23 & -0.03 \\
UK & - & 0.73 & 1.32 & 0.77 & 1.19 & 1.14 & 1.01 \\
US & 0.60 & 1.38 & 1.59 & 0.87 & 1.82 & 0.99 & 1.37 \\
Other European & & & & & & 1.02 & 1.10 \\
Countries & 0.60 & 1.01 & 1.12 & 1.13 & 1.02 & 1.03 \\
Australasia & -0.03 & 0.68 & 0.77 & 0.95 & 0.85 & 0.78 & 0.74 \\
Asian Countries & 0.73 & 1.39 & 0.70 & 0.40 & 1.14 & 1.04 & 1.06 \\
\hline Sector Total & 0.23 & 0.76 & 0.91 & 0.85 & 1.00 & 0.74 & 0.82 \\
\hline
\end{tabular}

Notes: Other European Countries include Belgium, Denmark, Finland, Ireland, Italy, Netherlands, Norway, Spain, Sweden, and Switzerland. Australia includes New Zealand. Asian Countries include Hong Kong,

Malaysia and Singapore. Others in sector include Resources, Transport, Utilities and Other sectors. 
Table 2 Properties of Factor Mimicking Portfolios

\section{A. Factor Mimicking Portfolios Non-Standardised for Accounting Difference between Countries}

A1. First Four Moments of Factor Mimicking Portfolios

\begin{tabular}{|c|rrrr|}
\hline & FVL & FGR & FDE & \multicolumn{1}{c|}{ FSZ } \\
\hline Mean & -1.7531 & 0.5459 & -0.0511 & -0.3827 \\
Standard Error & 3.2556 & 2.7048 & 1.6730 & 5.6489 \\
Skewness & -0.2733 & -0.3728 & 0.2717 & 0.6669 \\
Excess Kurtosis & 4.6677 & 1.8442 & 1.0137 & 2.7503 \\
\hline
\end{tabular}

A2. Correlation Matrix of Factor Mimicking Portfolios

\begin{tabular}{|l|rrrr|}
\hline & \multicolumn{1}{|c|}{ FVL } & FGR & FDE & FSZ \\
\hline FVL & 1.000 & & & \\
FGR & 0.316 & 1.000 & & \\
FDE & 0.193 & -0.118 & 1.000 & \\
FSZ & -0.677 & -0.703 & 0.094 & 1.000 \\
\hline
\end{tabular}

B. Factor Mimicking Portfolios Standardised for Accounting Difference between Countries

B1. First Four Moments of Factor Mimicking Portfolios

\begin{tabular}{|c|rrrr|}
\hline & \multicolumn{1}{|c}{ FVL } & FGR & \multicolumn{1}{c|}{ FDE } & \multicolumn{1}{c|}{ FSZ } \\
\hline Mean & -1.7583 & 0.1458 & -0.1434 & -0.3827 \\
Standard Error & 1.4566 & 1.1220 & 1.7095 & 5.6489 \\
Skewness & -0.9160 & -0.0168 & -0.1586 & 0.6669 \\
Excess Kurtosis & 1.6765 & 0.3800 & 1.1309 & 2.7503 \\
\hline
\end{tabular}

B2. Correlation Matrix of Factor Mimicking Portfolios

\begin{tabular}{|l|rrrr|}
\hline & \multicolumn{1}{|l}{ FVL } & FGR & FDE & FSZ \\
\hline FVL & 1.000 & & & \\
FGR & -0.201 & 1.000 & & \\
FDE & 0.081 & 0.126 & 1.000 & \\
FSZ & -0.065 & -0.139 & -0.204 & 1.000 \\
\hline
\end{tabular}


Table 3 Posterior Probabilities of 16 Combinations of FMPs for Country - Sector Grids

Value Weighted Returns and Non-Standardised for Different Accounting Regimes of Different Countries

A. Posterior Probabilities of 16 Combinations of FMPs Averaged over Countries

\begin{tabular}{|c|c|c|c|c|c|c|c|c|c|c|c|c|c|c|c|c|}
\hline Country & FVL & FGR & FDE & FSZ & $\begin{array}{l}\text { FVL, } \\
\text { FGR }\end{array}$ & $\begin{array}{l}\text { FVL, } \\
\text { FDE }\end{array}$ & $\begin{array}{l}\text { FVL, } \\
\text { FSZ }\end{array}$ & $\begin{array}{l}\text { FGR, } \\
\text { FDE }\end{array}$ & $\begin{array}{l}\text { FGR, } \\
\text { FSZ }\end{array}$ & $\begin{array}{l}\text { FDE, } \\
\text { FSZ }\end{array}$ & $\begin{array}{l}\text { FVL, FGR, } \\
\text { FDE }\end{array}$ & $\begin{array}{c}\text { FVL, FGR, } \\
\text { FSZ }\end{array}$ & $\begin{array}{l}\text { FVL, FDE, } \\
\text { FSZ }\end{array}$ & $\begin{array}{c}\text { FGR, FDE, } \\
\text { FSZ }\end{array}$ & $\begin{array}{l}\text { FVL, FGR, } \\
\text { FDE, FSZ }\end{array}$ & None \\
\hline Canada & 0.09 & 0.11 & 0.08 & 0.07 & 0.04 & 0.01 & 0.02 & 0.02 & 0.05 & 0.01 & 0.01 & 0.05 & 0.00 & 0.01 & 0.01 & 0.43 \\
\hline France & 0.08 & 0.09 & 0.09 & 0.09 & 0.01 & 0.01 & 0.01 & 0.01 & 0.03 & 0.01 & 0.00 & 0.01 & 0.00 & 0.00 & 0.00 & 0.53 \\
\hline Germany & 0.08 & 0.15 & 0.06 & 0.07 & 0.04 & 0.01 & 0.01 & 0.02 & 0.04 & 0.01 & 0.00 & 0.01 & 0.00 & 0.01 & 0.00 & 0.49 \\
\hline Japan & 0.07 & 0.15 & 0.09 & 0.10 & 0.05 & 0.03 & 0.04 & 0.08 & 0.05 & 0.04 & 0.02 & 0.01 & 0.01 & 0.02 & 0.01 & 0.24 \\
\hline UK & 0.12 & 0.09 & 0.10 & 0.07 & 0.02 & 0.03 & 0.02 & 0.03 & 0.03 & 0.02 & 0.01 & 0.00 & 0.01 & 0.01 & 0.00 & 0.45 \\
\hline US & 0.10 & 0.09 & 0.10 & 0.11 & 0.02 & 0.02 & 0.02 & 0.03 & 0.03 & 0.03 & 0.01 & 0.01 & 0.01 & 0.01 & 0.00 & 0.41 \\
\hline Australasia & 0.11 & 0.09 & 0.09 & 0.08 & 0.02 & 0.02 & 0.02 & 0.02 & 0.03 & 0.01 & 0.01 & 0.01 & 0.00 & 0.01 & 0.00 & 0.48 \\
\hline Asian Countries & 0.10 & 0.09 & 0.08 & 0.10 & 0.02 & 0.02 & 0.03 & 0.02 & 0.08 & 0.02 & 0.00 & 0.06 & 0.01 & 0.01 & 0.02 & 0.35 \\
\hline
\end{tabular}

\section{B. Posterior Probabilities of 16 Combinations of FMPs Averaged over Sectors}

\begin{tabular}{|c|c|c|c|c|c|c|c|c|c|c|c|c|c|c|c|c|}
\hline Sector & FVL & FGR & FDE & FSZ & $\begin{array}{l}\text { FVL, } \\
\text { FGR }\end{array}$ & $\begin{array}{l}\text { FVL, } \\
\text { FDE }\end{array}$ & $\begin{array}{l}\text { FVL, } \\
\text { FSZ }\end{array}$ & $\begin{array}{l}\text { FGR, } \\
\text { FDE }\end{array}$ & $\begin{array}{l}\text { FGR, } \\
\text { FSZ }\end{array}$ & $\begin{array}{l}\text { FDE, } \\
\text { FSZ }\end{array}$ & $\begin{array}{l}\text { FVL, FGR, } \\
\text { FDE }\end{array}$ & $\begin{array}{l}\text { FVL, FGR, } \\
\text { FSZ }\end{array}$ & $\begin{array}{c}\text { FVL, FDE, } \\
\text { FSZ }\end{array}$ & $\begin{array}{c}\text { FGR, FDE, } \\
\text { FSZ }\end{array}$ & $\begin{array}{l}\text { FVL, FGR, } \\
\text { FDE, FSZ }\end{array}$ & None \\
\hline Basic Industries & 0.10 & 0.12 & 0.07 & 0.08 & 0.02 & 0.02 & 0.02 & 0.02 & 0.04 & 0.03 & 0.00 & 0.01 & 0.00 & 0.01 & 0.00 & 0.45 \\
\hline Capital Goods & 0.08 & 0.10 & 0.09 & 0.09 & 0.03 & 0.03 & 0.02 & 0.04 & 0.05 & 0.02 & 0.01 & 0.02 & 0.01 & 0.01 & 0.00 & 0.39 \\
\hline Energy & 0.07 & 0.08 & 0.11 & 0.09 & 0.02 & 0.01 & 0.01 & 0.02 & 0.03 & 0.02 & 0.00 & 0.01 & 0.00 & 0.00 & 0.00 & 0.52 \\
\hline Financials & 0.08 & 0.14 & 0.07 & 0.09 & 0.03 & 0.02 & 0.02 & 0.03 & 0.06 & 0.02 & 0.01 & 0.02 & 0.01 & 0.01 & 0.01 & 0.37 \\
\hline Others & 0.11 & 0.09 & 0.07 & 0.08 & 0.03 & 0.02 & 0.03 & 0.02 & 0.05 & 0.02 & 0.01 & 0.05 & 0.01 & 0.01 & 0.02 & 0.38 \\
\hline
\end{tabular}


C. Posterior Probabilities of 16 Combinations of FMPs for Country - Sector Grids

\begin{tabular}{|c|c|c|c|c|c|c|c|c|c|c|c|c|c|c|c|c|c|}
\hline Country & Sector & FVL & FGR & FDE & FSZ & $\begin{array}{l}\text { FVL, } \\
\text { FGR }\end{array}$ & $\begin{array}{l}\text { FVL, } \\
\text { FDE }\end{array}$ & $\begin{array}{l}\text { FVL, } \\
\text { FSZ }\end{array}$ & $\begin{array}{l}\text { FGR, } \\
\text { FDE }\end{array}$ & $\begin{array}{l}\text { FGR, } \\
\text { FSZ }\end{array}$ & $\begin{array}{l}\text { FDE, } \\
\text { FSZ }\end{array}$ & $\begin{array}{l}\text { FVL, FGR, } \\
\text { FDE }\end{array}$ & $\begin{array}{c}\text { FVL, FGR, } \\
\text { FSZ }\end{array}$ & $\begin{array}{c}\text { FVL, FDE, } \\
\text { FSZ }\end{array}$ & $\begin{array}{c}\text { FGR, FDE, } \\
\text { FSZ }\end{array}$ & $\begin{array}{l}\text { FVL, FGR, } \\
\text { FDE, FSZ }\end{array}$ & None \\
\hline \multirow[t]{6}{*}{ Canada } & Basic Industries & 0.11 & 0.08 & 0.07 & 0.08 & 0.01 & 0.01 & 0.01 & 0.01 & 0.01 & 0.01 & 0.00 & 0.00 & 0.00 & 0.00 & 0.00 & $\mathbf{0 . 5 9}$ \\
\hline & Capital Goods & 0.06 & 0.14 & 0.05 & 0.04 & 0.12 & 0.01 & 0.02 & 0.02 & 0.12 & 0.01 & 0.02 & 0.02 & 0.01 & 0.02 & 0.00 & 0.35 \\
\hline & Consumer Goods & 0.07 & 0.10 & 0.13 & 0.08 & 0.02 & 0.02 & 0.02 & 0.03 & 0.01 & 0.02 & 0.00 & 0.00 & 0.00 & 0.00 & 0.00 & 0.50 \\
\hline & Energy & 0.07 & 0.13 & 0.11 & 0.08 & 0.03 & 0.01 & 0.02 & 0.02 & 0.06 & 0.01 & 0.00 & 0.01 & 0.00 & 0.01 & 0.00 & 0.42 \\
\hline & Financials & 0.10 & 0.15 & 0.05 & 0.09 & 0.03 & 0.01 & 0.03 & 0.02 & 0.05 & 0.01 & 0.00 & 0.01 & 0.00 & 0.01 & 0.00 & 0.43 \\
\hline & Others & 0.10 & 0.04 & 0.08 & 0.06 & 0.01 & 0.02 & 0.03 & 0.02 & 0.05 & 0.02 & 0.00 & 0.23 & 0.01 & 0.02 & 0.05 & 0.25 \\
\hline \multirow[t]{6}{*}{ France } & Basic Industries & - & $\cdot$ & . & 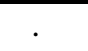 & - & 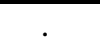 & - & &. & & & & & & . & . \\
\hline & Capital Goods & 0.06 & 0.08 & 0.13 & 0.11 & 0.01 & 0.02 & 0.02 & 0.02 & 0.08 & 0.02 & 0.00 & 0.02 & 0.00 & 0.01 & 0.00 & 0.42 \\
\hline & Consumer Goods & 0.11 & 0.08 & 0.11 & 0.08 & 0.02 & 0.02 & 0.02 & 0.01 & 0.01 & 0.02 & 0.00 & 0.00 & 0.00 & 0.00 & 0.00 & 0.53 \\
\hline & Energy & 0.07 & 0.06 & 0.08 & 0.07 & 0.01 & 0.01 & 0.01 & 0.01 & 0.01 & 0.01 & 0.00 & 0.00 & 0.00 & 0.00 & 0.00 & 0.66 \\
\hline & Financials & 0.07 & 0.18 & 0.05 & 0.10 & 0.03 & 0.01 & 0.02 & 0.02 & 0.06 & 0.01 & 0.00 & 0.01 & 0.00 & 0.01 & 0.00 & 0.44 \\
\hline & Others & 0.11 & 0.06 & 0.08 & 0.08 & 0.01 & 0.02 & 0.01 & 0.01 & 0.01 & 0.01 & 0.00 & 0.00 & 0.00 & 0.00 & 0.00 & 0.58 \\
\hline \multirow[t]{6}{*}{ Germany } & Basic Industries & 0.06 & 0.10 & 0.06 & 0.06 & 0.01 & 0.01 & 0.01 & 0.01 & 0.04 & 0.01 & 0.00 & 0.01 & 0.00 & 0.00 & 0.00 & 0.62 \\
\hline & Capital Goods & 0.08 & 0.13 & 0.07 & 0.10 & 0.02 & 0.01 & 0.01 & 0.03 & 0.03 & 0.01 & 0.00 & 0.01 & 0.00 & 0.00 & 0.00 & 0.48 \\
\hline & Consumer Goods & 0.13 & 0.10 & 0.08 & 0.07 & 0.02 & 0.02 & 0.02 & 0.02 & 0.02 & 0.01 & 0.00 & 0.00 & 0.00 & 0.00 & 0.00 & 0.51 \\
\hline & Energy & . & . & • & & . & 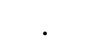 & . & & . & & & & & $\cdot$ & . & . \\
\hline & Financials & 0.05 & 0.25 & 0.04 & 0.07 & 0.04 & 0.01 & 0.01 & 0.04 & 0.07 & 0.01 & 0.00 & 0.01 & 0.00 & 0.01 & 0.00 & 0.38 \\
\hline & Others & 0.08 & 0.16 & 0.05 & 0.04 & 0.09 & 0.01 & 0.01 & 0.02 & 0.05 & 0.00 & 0.01 & 0.01 & 0.00 & 0.01 & 0.00 & 0.45 \\
\hline \multirow[t]{6}{*}{ Japan } & Basic Industries & 0.06 & 0.17 & 0.08 & 0.16 & 0.02 & 0.01 & 0.05 & 0.03 & 0.03 & 0.08 & 0.00 & 0.01 & 0.01 & 0.01 & 0.00 & 0.27 \\
\hline & Capital Goods & 0.05 & 0.15 & 0.08 & 0.07 & 0.05 & 0.04 & 0.02 & 0.17 & 0.05 & 0.05 & 0.05 & 0.01 & 0.01 & 0.05 & 0.01 & 0.15 \\
\hline & Consumer Goods & 0.07 & 0.20 & 0.08 & 0.08 & 0.04 & 0.03 & 0.03 & 0.11 & 0.05 & 0.03 & 0.03 & 0.01 & 0.01 & 0.03 & 0.01 & 0.19 \\
\hline & Energy & 0.10 & 0.06 & 0.15 & 0.08 & 0.01 & 0.02 & 0.01 & 0.02 & 0.01 & 0.02 & 0.00 & 0.00 & 0.00 & 0.00 & 0.00 & 0.50 \\
\hline & Financials & 0.08 & 0.14 & 0.06 & 0.12 & 0.08 & 0.03 & 0.03 & 0.06 & 0.11 & 0.03 & 0.03 & 0.03 & 0.01 & 0.02 & 0.01 & 0.16 \\
\hline & Others & 0.06 & 0.17 & 0.07 & 0.09 & 0.07 & 0.02 & 0.07 & 0.07 & 0.06 & 0.03 & 0.02 & 0.03 & 0.04 & 0.02 & 0.01 & 0.19 \\
\hline
\end{tabular}




\begin{tabular}{|c|c|c|c|c|c|c|c|c|c|c|c|c|c|c|c|c|c|}
\hline \multirow[t]{5}{*}{ UK } & Basic Industries & . & & 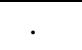 & & . & 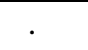 & . & & . & $\cdot$ & & . & $\cdot$ & & & . \\
\hline & Capital Goods & 0.09 & 0.06 & 0.16 & 0.07 & 0.02 & 0.07 & 0.02 & 0.04 & 0.01 & 0.03 & 0.02 & 0.00 & 0.01 & 0.01 & 0.00 & 0.38 \\
\hline & Consumer Goods & 0.11 & 0.07 & 0.10 & 0.07 & 0.02 & 0.02 & 0.03 & 0.02 & 0.01 & 0.02 & 0.00 & 0.00 & 0.01 & 0.00 & 0.00 & 0.51 \\
\hline & Energy & 0.06 & 0.07 & 0.09 & 0.06 & 0.01 & 0.01 & 0.01 & 0.01 & 0.03 & 0.01 & 0.00 & 0.00 & 0.00 & 0.00 & 0.00 & 0.64 \\
\hline & Others & 0.27 & 0.05 & 0.09 & 0.07 & 0.04 & 0.04 & 0.04 & 0.03 & 0.01 & 0.02 & 0.01 & 0.01 & 0.01 & 0.00 & 0.00 & 0.31 \\
\hline \multirow[t]{6}{*}{ US } & Basic Industries & 0.11 & 0.11 & 0.10 & 0.09 & 0.02 & 0.03 & 0.02 & 0.05 & 0.01 & 0.02 & 0.01 & 0.00 & 0.00 & 0.01 & 0.00 & 0.43 \\
\hline & Capital Goods & 0.12 & 0.09 & 0.08 & 0.11 & 0.03 & 0.02 & 0.03 & 0.02 & 0.03 & 0.03 & 0.01 & 0.01 & 0.01 & 0.01 & 0.00 & 0.39 \\
\hline & Consumer Goods & 0.10 & 0.09 & 0.09 & 0.10 & 0.02 & 0.02 & 0.02 & 0.01 & 0.03 & 0.02 & 0.00 & 0.01 & 0.01 & 0.00 & 0.00 & 0.47 \\
\hline & Energy & 0.04 & 0.08 & 0.16 & 0.13 & 0.01 & 0.02 & 0.02 & 0.02 & 0.02 & 0.03 & 0.00 & 0.00 & 0.00 & 0.00 & 0.00 & 0.44 \\
\hline & Financials & 0.10 & 0.12 & 0.09 & 0.10 & 0.03 & 0.03 & 0.02 & 0.04 & 0.05 & 0.03 & 0.01 & 0.01 & 0.01 & 0.02 & 0.00 & 0.33 \\
\hline & Others & 0.10 & 0.07 & 0.08 & 0.11 & 0.02 & 0.02 & 0.02 & 0.02 & 0.05 & 0.03 & 0.00 & 0.04 & 0.01 & 0.01 & 0.02 & 0.40 \\
\hline Other & Basic Industries & 0.09 & 0.06 & 0.11 & 0.08 & 0.01 & 0.04 & 0.01 & 0.03 & 0.07 & 0.05 & 0.01 & 0.01 & 0.01 & 0.01 & 0.00 & 0.43 \\
\hline European & Capital Goods & 0.10 & 0.09 & 0.09 & 0.10 & 0.02 & 0.02 & 0.03 & 0.01 & 0.02 & 0.02 & 0.00 & 0.01 & 0.00 & 0.00 & 0.00 & 0.50 \\
\hline \multirow[t]{3}{*}{ Countries } & Consumer Goods & 0.11 & 0.11 & 0.08 & 0.10 & 0.02 & 0.02 & 0.02 & 0.02 & 0.02 & 0.02 & 0.00 & 0.01 & 0.00 & 0.00 & 0.00 & 0.46 \\
\hline & Energy & 0.12 & 0.08 & 0.05 & 0.12 & 0.04 & 0.02 & 0.02 & 0.01 & 0.06 & 0.01 & 0.00 & 0.01 & 0.00 & 0.01 & 0.00 & 0.44 \\
\hline & Financials & 0.09 & 0.10 & 0.09 & 0.09 & 0.02 & 0.02 & 0.04 & 0.02 & 0.02 & 0.01 & 0.00 & 0.01 & 0.02 & 0.00 & 0.00 & 0.48 \\
\hline \multirow[t]{6}{*}{ Australasia } & Basic Industries & 0.17 & 0.07 & 0.06 & 0.07 & 0.03 & 0.02 & 0.03 & 0.01 & 0.01 & 0.01 & 0.00 & 0.00 & 0.00 & 0.00 & 0.00 & 0.50 \\
\hline & Capital Goods & 0.10 & 0.10 & 0.07 & 0.08 & 0.02 & 0.01 & 0.01 & 0.01 & 0.01 & 0.01 & 0.00 & 0.00 & 0.00 & 0.00 & 0.00 & 0.56 \\
\hline & Consumer Goods & 0.11 & 0.09 & 0.11 & 0.08 & 0.02 & 0.04 & 0.02 & 0.02 & 0.01 & 0.02 & 0.01 & 0.00 & 0.01 & 0.00 & 0.00 & 0.46 \\
\hline & Energy & 0.05 & 0.10 & 0.13 & 0.05 & 0.01 & 0.01 & 0.00 & 0.03 & 0.02 & 0.01 & 0.00 & 0.00 & 0.00 & 0.01 & 0.00 & 0.56 \\
\hline & Financials & 0.10 & 0.07 & 0.09 & 0.13 & 0.03 & 0.02 & 0.03 & 0.02 & 0.04 & 0.02 & 0.02 & 0.01 & 0.01 & 0.01 & 0.00 & 0.40 \\
\hline & Others & 0.11 & 0.10 & 0.05 & 0.07 & 0.03 & 0.01 & 0.04 & 0.01 & 0.09 & 0.01 & 0.00 & 0.05 & 0.00 & 0.01 & 0.01 & 0.40 \\
\hline \multirow{6}{*}{$\begin{array}{c}\text { Asian } \\
\text { Countries }\end{array}$} & Basic Industries & 0.08 & 0.25 & 0.04 & 0.04 & 0.04 & 0.01 & 0.01 & 0.03 & 0.07 & 0.00 & 0.00 & 0.06 & 0.00 & 0.01 & 0.01 & 0.34 \\
\hline & Capital Goods & 0.08 & 0.05 & 0.05 & 0.17 & 0.01 & 0.02 & 0.04 & 0.01 & 0.12 & 0.02 & 0.00 & 0.08 & 0.00 & 0.02 & 0.02 & 0.29 \\
\hline & Consumer Goods & 0.08 & 0.05 & 0.11 & 0.16 & 0.01 & 0.04 & 0.04 & 0.01 & 0.04 & 0.04 & 0.00 & 0.03 & 0.01 & 0.01 & 0.00 & 0.36 \\
\hline & Energy & 0.24 & 0.05 & 0.05 & 0.06 & 0.02 & 0.02 & 0.03 & 0.00 & 0.01 & 0.01 & 0.00 & 0.00 & 0.00 & 0.00 & 0.00 & 0.50 \\
\hline & Financials & 0.06 & 0.06 & 0.12 & 0.07 & 0.01 & 0.04 & 0.01 & 0.04 & 0.06 & 0.03 & 0.01 & 0.09 & 0.01 & 0.01 & 0.03 & 0.33 \\
\hline & Others & 0.06 & 0.06 & 0.09 & 0.09 & 0.01 & 0.02 & 0.03 & 0.02 & 0.14 & 0.02 & 0.00 & 0.09 & 0.01 & 0.02 & 0.06 & 0.29 \\
\hline \multicolumn{2}{|l|}{ Average } & 0.09 & 0.10 & 0.08 & 0.09 & 0.03 & 0.02 & 0.02 & 0.03 & 0.04 & 0.02 & 0.01 & 0.02 & 0.01 & 0.01 & 0.01 & 0.42 \\
\hline
\end{tabular}

Notes: Bolded numbers represent the highest posterior probability in each country/sector grid or the posterior probability which is larger than or equal to 0.2 . 
Table 4 Posterior Probabilities of 16 Combinations of FMPs for Country - Sector Grids

Value Weighted Returns and Standardised for Different Accounting Regimes of Different Countries

A. Posterior Probabilities of 16 Combinations of FMPs Averaged over Countries

\begin{tabular}{|c|c|c|c|c|c|c|c|c|c|c|c|c|c|c|c|c|}
\hline Country & FVL & FGR & FDE & FSZ & $\begin{array}{l}\text { FVL, } \\
\text { FGR }\end{array}$ & $\begin{array}{l}\text { FVL, } \\
\text { FDE }\end{array}$ & $\begin{array}{c}\text { FVL, } \\
\text { FSZ }\end{array}$ & $\begin{array}{l}\text { FGR, } \\
\text { FDE }\end{array}$ & $\begin{array}{c}\text { FGR, } \\
\text { FSZ }\end{array}$ & $\begin{array}{c}\text { FDE, } \\
\text { FSZ }\end{array}$ & $\begin{array}{l}\text { FVL, FGR, } \\
\text { FDE }\end{array}$ & $\begin{array}{c}\text { FVL, FGR, } \\
\text { FSZ }\end{array}$ & $\begin{array}{l}\text { FVL, FDE, } \\
\text { FSZ }\end{array}$ & $\begin{array}{c}\text { FGR, FDE, } \\
\text { FSZ }\end{array}$ & $\begin{array}{c}\text { FVL, FGR, } \\
\text { FDE, FSZ }\end{array}$ & None \\
\hline Canada & 0.12 & 0.11 & 0.08 & 0.08 & 0.03 & 0.02 & 0.02 & 0.04 & 0.02 & 0.01 & 0.01 & 0.01 & 0.00 & 0.01 & 0.00 & 0.43 \\
\hline France & 0.14 & 0.10 & 0.07 & 0.08 & 0.03 & 0.02 & 0.03 & 0.01 & 0.02 & 0.01 & 0.00 & 0.01 & 0.00 & 0.00 & 0.00 & 0.45 \\
\hline Germany & 0.10 & 0.12 & 0.09 & 0.08 & 0.02 & 0.02 & 0.02 & 0.03 & 0.02 & 0.01 & 0.00 & 0.00 & 0.00 & 0.01 & 0.00 & 0.48 \\
\hline Japan & 0.08 & 0.08 & 0.09 & 0.12 & 0.03 & 0.03 & 0.08 & 0.03 & 0.04 & 0.06 & 0.01 & 0.02 & 0.05 & 0.02 & 0.01 & 0.25 \\
\hline UK & 0.11 & 0.12 & 0.10 & 0.07 & 0.03 & 0.03 & 0.03 & 0.02 & 0.03 & 0.01 & 0.01 & 0.01 & 0.01 & 0.00 & 0.00 & 0.41 \\
\hline US & 0.13 & 0.09 & 0.08 & 0.11 & 0.03 & 0.03 & 0.04 & 0.02 & 0.03 & 0.03 & 0.01 & 0.01 & 0.01 & 0.01 & 0.00 & 0.39 \\
\hline Other European Countries & 0.11 & 0.12 & 0.12 & 0.09 & 0.03 & 0.05 & 0.02 & 0.03 & 0.03 & 0.02 & 0.01 & 0.01 & 0.01 & 0.01 & 0.00 & 0.35 \\
\hline Australasia & 0.13 & 0.09 & 0.07 & 0.09 & 0.03 & 0.02 & 0.02 & 0.01 & 0.01 & 0.01 & 0.00 & 0.00 & 0.00 & 0.00 & 0.00 & 0.50 \\
\hline Asian Countries & 0.15 & 0.09 & 0.05 & 0.09 & 0.04 & 0.03 & 0.04 & 0.02 & 0.05 & 0.02 & 0.01 & 0.02 & 0.01 & 0.02 & 0.01 & 0.34 \\
\hline
\end{tabular}

B. Posterior Probabilities of 16 Combinations of FMPs Averaged over Sectors

\begin{tabular}{|c|c|c|c|c|c|c|c|c|c|c|c|c|c|c|c|c|}
\hline Sector & FVL & FGR & FDE & FSZ & $\begin{array}{l}\text { FVL, } \\
\text { FGR }\end{array}$ & $\begin{array}{l}\text { FVL, } \\
\text { FDE }\end{array}$ & $\begin{array}{l}\text { FVL, } \\
\text { FSZ }\end{array}$ & $\begin{array}{l}\text { FGR, } \\
\text { FDE }\end{array}$ & $\begin{array}{l}\text { FGR, } \\
\text { FSZ }\end{array}$ & $\begin{array}{l}\text { FDE, } \\
\text { FSZ }\end{array}$ & $\begin{array}{c}\text { FVL, FGR, } \\
\text { FDE }\end{array}$ & $\begin{array}{c}\text { FVL, } \\
\text { FGR, FSZ }\end{array}$ & $\begin{array}{l}\text { FVL, FDE, } \\
\text { FSZ }\end{array}$ & $\begin{array}{c}\text { FGR, } \\
\text { FDE, FSZ }\end{array}$ & $\begin{array}{c}\text { FVL, } \\
\text { FGR, FDE, } \\
\text { FSZ }\end{array}$ & None \\
\hline Basic Industries & 0.12 & 0.08 & 0.08 & 0.10 & 0.02 & 0.02 & 0.03 & 0.01 & 0.02 & 0.02 & 0.00 & 0.00 & 0.00 & 0.00 & 0.00 & 0.49 \\
\hline Capital Goods & 0.12 & 0.09 & 0.09 & 0.09 & 0.03 & 0.03 & 0.04 & 0.02 & 0.04 & 0.03 & 0.01 & 0.01 & 0.02 & 0.02 & 0.01 & 0.36 \\
\hline Consumer Goods & 0.12 & 0.09 & 0.09 & 0.09 & 0.03 & 0.03 & 0.03 & 0.02 & 0.03 & 0.02 & 0.01 & 0.01 & 0.01 & 0.01 & 0.00 & 0.41 \\
\hline Energy & 0.08 & 0.11 & 0.10 & 0.06 & 0.02 & 0.03 & 0.01 & 0.03 & 0.02 & 0.02 & 0.01 & 0.00 & 0.01 & 0.01 & 0.00 & 0.37 \\
\hline Financials & 0.11 & 0.10 & 0.08 & 0.11 & 0.03 & 0.03 & 0.03 & 0.03 & 0.03 & 0.03 & 0.01 & 0.01 & 0.01 & 0.01 & 0.00 & 0.39 \\
\hline Others & 0.13 & 0.12 & 0.07 & 0.09 & 0.04 & 0.02 & 0.04 & 0.02 & 0.03 & 0.02 & 0.01 & 0.02 & 0.01 & 0.01 & 0.01 & 0.36 \\
\hline
\end{tabular}


C. Posterior Probabilities of 16 Combinations of FMPs for Country - Sector Grids

\begin{tabular}{|c|c|c|c|c|c|c|c|c|c|c|c|c|c|c|c|c|c|}
\hline Country & Sector & FVL & FGR & FDE & FSZ & $\begin{array}{l}\text { FVL, } \\
\text { FGR }\end{array}$ & $\begin{array}{l}\text { FVL, } \\
\text { FDE }\end{array}$ & $\begin{array}{l}\text { FVL, } \\
\text { FSZ }\end{array}$ & $\begin{array}{l}\text { FGR, } \\
\text { FDE }\end{array}$ & $\begin{array}{l}\text { FGR, } \\
\text { FSZ }\end{array}$ & $\begin{array}{l}\text { FDE, } \\
\text { FSZ }\end{array}$ & $\begin{array}{c}\text { FVL, FGR, } \\
\text { FDE }\end{array}$ & $\begin{array}{c}\text { FVL, } \\
\text { FGR, FSZ }\end{array}$ & $\begin{array}{l}\text { FVL, FDE, } \\
\quad \text { FSZ }\end{array}$ & $\begin{array}{c}\text { FGR, } \\
\text { FDE, FSZ }\end{array}$ & $\begin{array}{c}\text { FVL, } \\
\text { FGR, FDE, } \\
\text { FSZ }\end{array}$ & None \\
\hline \multirow[t]{6}{*}{ Canada } & Basic Industries & 0.08 & 0.06 & 0.11 & 0.08 & 0.01 & 0.02 & 0.01 & 0.01 & 0.01 & 0.02 & 0.00 & 0.00 & 0.00 & 0.00 & 0.00 & 0.58 \\
\hline & Capital Goods & 0.23 & 0.06 & 0.05 & 0.06 & 0.03 & 0.04 & 0.02 & 0.01 & 0.01 & 0.01 & 0.01 & 0.00 & 0.00 & 0.00 & 0.00 & 0.47 \\
\hline & Consumer Goods & 0.14 & 0.10 & 0.08 & 0.08 & 0.02 & 0.03 & 0.02 & 0.03 & 0.01 & 0.01 & 0.01 & 0.00 & 0.00 & 0.00 & 0.00 & 0.46 \\
\hline & Energy & 0.10 & 0.21 & 0.05 & 0.08 & 0.03 & 0.01 & 0.02 & 0.05 & 0.04 & 0.01 & 0.01 & 0.01 & 0.00 & 0.01 & 0.00 & 0.38 \\
\hline & Financials & 0.06 & 0.10 & 0.16 & 0.06 & 0.02 & 0.03 & 0.01 & 0.12 & 0.02 & 0.03 & 0.01 & 0.00 & 0.00 & 0.03 & 0.00 & 0.35 \\
\hline & Others & 0.10 & 0.13 & 0.04 & 0.09 & 0.10 & 0.01 & 0.04 & 0.01 & 0.03 & 0.02 & 0.02 & 0.04 & 0.01 & 0.01 & 0.01 & $\mathbf{0 . 3 3}$ \\
\hline \multirow[t]{6}{*}{ France } & Basic Industries & . & 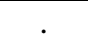 & 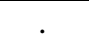 & . & . & & . & $\cdot$ & . & 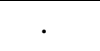 & & & 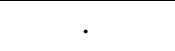 & & & . \\
\hline & Capital Goods & 0.09 & 0.10 & 0.14 & 0.11 & 0.02 & 0.02 & 0.03 & 0.02 & 0.04 & 0.04 & 0.00 & 0.01 & 0.01 & 0.01 & 0.00 & 0.37 \\
\hline & Consumer Goods & 0.10 & 0.12 & 0.07 & 0.07 & 0.04 & 0.02 & 0.03 & 0.02 & 0.02 & 0.01 & 0.01 & 0.01 & 0.01 & 0.00 & 0.00 & 0.48 \\
\hline & Energy & 0.20 & 0.06 & 0.06 & 0.06 & 0.03 & 0.03 & 0.02 & 0.01 & 0.01 & 0.01 & 0.00 & 0.00 & 0.00 & 0.00 & 0.00 & 0.51 \\
\hline & Financials & 0.14 & 0.11 & 0.05 & 0.11 & 0.02 & 0.02 & 0.03 & 0.01 & 0.02 & 0.01 & 0.00 & 0.00 & 0.00 & 0.00 & 0.00 & 0.46 \\
\hline & Others & 0.19 & 0.10 & 0.05 & 0.07 & 0.03 & 0.02 & 0.03 & 0.01 & 0.02 & 0.01 & 0.00 & 0.00 & 0.00 & 0.00 & 0.00 & 0.46 \\
\hline \multirow[t]{6}{*}{ Germany } & Basic Industries & 0.08 & 0.08 & 0.06 & 0.07 & 0.01 & 0.01 & 0.01 & 0.01 & 0.01 & 0.01 & 0.00 & 0.00 & 0.00 & 0.00 & 0.00 & 0.67 \\
\hline & Capital Goods & 0.08 & 0.10 & 0.09 & 0.11 & 0.02 & 0.02 & 0.02 & 0.05 & 0.02 & 0.02 & 0.01 & 0.00 & 0.01 & 0.02 & 0.00 & 0.44 \\
\hline & Consumer Goods & 0.09 & 0.11 & 0.12 & 0.06 & 0.03 & 0.02 & 0.01 & 0.02 & 0.02 & 0.01 & 0.00 & 0.01 & 0.00 & 0.00 & 0.00 & 0.48 \\
\hline & Energy & · & . & $\cdot$ & - & $\cdot$ & . & · & . & . & • & • & & $\cdot$ & $\cdot$ & $\cdot$ & - \\
\hline & Financials & 0.09 & 0.12 & 0.06 & 0.12 & 0.02 & 0.01 & 0.03 & 0.01 & 0.03 & 0.01 & 0.00 & 0.00 & 0.00 & 0.00 & 0.00 & 0.48 \\
\hline & Others & 0.15 & 0.21 & 0.10 & 0.03 & 0.04 & 0.04 & 0.02 & 0.03 & 0.02 & 0.01 & 0.01 & 0.00 & 0.01 & 0.00 & 0.00 & $\mathbf{0 . 3 3}$ \\
\hline \multirow[t]{6}{*}{ Japan } & Basic Industries & 0.06 & 0.07 & 0.10 & 0.20 & 0.02 & 0.02 & 0.09 & 0.03 & 0.04 & 0.04 & 0.01 & 0.02 & 0.02 & 0.01 & 0.00 & 0.28 \\
\hline & Capital Goods & 0.08 & 0.05 & 0.08 & 0.10 & 0.02 & 0.04 & 0.11 & 0.02 & 0.04 & 0.10 & 0.01 & 0.03 & 0.12 & 0.03 & 0.03 & 0.16 \\
\hline & Consumer Goods & 0.06 & 0.08 & 0.08 & 0.13 & 0.02 & 0.03 & 0.08 & 0.02 & 0.04 & 0.06 & 0.01 & 0.03 & 0.04 & 0.03 & 0.01 & 0.26 \\
\hline & Energy & 0.05 & 0.14 & 0.11 & 0.07 & 0.04 & 0.02 & 0.01 & 0.05 & 0.02 & 0.01 & 0.02 & 0.00 & 0.00 & 0.01 & 0.00 & 0.44 \\
\hline & Financials & 0.12 & 0.03 & 0.12 & 0.10 & 0.03 & 0.05 & 0.10 & 0.03 & 0.05 & 0.10 & 0.01 & 0.04 & 0.05 & 0.02 & 0.02 & 0.14 \\
\hline & Others & 0.11 & 0.10 & 0.06 & 0.11 & 0.04 & 0.02 & 0.11 & 0.03 & 0.04 & 0.06 & 0.01 & 0.03 & 0.04 & 0.02 & 0.01 & 0.21 \\
\hline
\end{tabular}




\begin{tabular}{|c|c|c|c|c|c|c|c|c|c|c|c|c|c|c|c|c|c|}
\hline \multirow[t]{5}{*}{ UK } & Basic Industries & & r. & & r. &. & . & . & $\cdot$ & 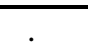 & 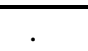 & & & 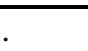 & & & • \\
\hline & Capital Goods & 0.15 & 0.16 & 0.06 & 0.06 & 0.06 & 0.04 & 0.03 & 0.02 & 0.04 & 0.02 & 0.01 & 0.02 & 0.01 & 0.01 & 0.00 & 0.31 \\
\hline & Consumer Goods & 0.13 & 0.13 & 0.08 & 0.06 & 0.04 & 0.04 & 0.04 & 0.02 & 0.02 & 0.01 & 0.01 & 0.01 & 0.01 & 0.00 & 0.00 & 0.40 \\
\hline & Energy & 0.09 & 0.08 & 0.20 & 0.05 & 0.02 & 0.04 & 0.01 & 0.03 & 0.01 & 0.02 & 0.01 & 0.00 & 0.00 & 0.00 & 0.00 & 0.45 \\
\hline & Others & 0.12 & 0.07 & 0.09 & 0.12 & 0.04 & 0.02 & 0.04 & 0.02 & 0.02 & 0.02 & 0.00 & 0.01 & 0.00 & 0.00 & 0.00 & 0.43 \\
\hline \multirow[t]{6}{*}{ US } & Basic Industries & 0.17 & 0.07 & 0.07 & 0.09 & 0.04 & 0.03 & 0.03 & 0.01 & 0.01 & 0.01 & 0.01 & 0.01 & 0.00 & 0.00 & 0.00 & 0.43 \\
\hline & Capital Goods & 0.15 & 0.10 & 0.09 & 0.09 & 0.05 & 0.04 & 0.05 & 0.03 & 0.04 & 0.03 & 0.01 & 0.02 & 0.01 & 0.01 & 0.00 & 0.29 \\
\hline & Consumer Goods & 0.18 & 0.07 & 0.08 & 0.09 & 0.03 & 0.03 & 0.04 & 0.02 & 0.02 & 0.02 & 0.01 & 0.01 & 0.01 & 0.01 & 0.00 & 0.39 \\
\hline & Energy & 0.06 & 0.12 & 0.09 & 0.12 & 0.03 & 0.01 & 0.02 & 0.02 & 0.03 & 0.04 & 0.00 & 0.01 & 0.01 & 0.01 & 0.00 & 0.44 \\
\hline & Financials & 0.10 & 0.09 & 0.09 & 0.15 & 0.02 & 0.03 & 0.04 & 0.02 & 0.02 & 0.03 & 0.01 & 0.01 & 0.01 & 0.00 & 0.00 & 0.39 \\
\hline & Others & 0.10 & 0.10 & 0.09 & 0.13 & 0.02 & 0.03 & 0.03 & 0.02 & 0.03 & 0.03 & 0.01 & 0.01 & 0.01 & 0.01 & 0.00 & 0.39 \\
\hline Other & Basic Industries & 0.10 & 0.12 & 0.11 & 0.12 & 0.02 & 0.02 & 0.02 & 0.02 & 0.04 & 0.03 & 0.00 & 0.00 & 0.00 & 0.01 & 0.00 & 0.38 \\
\hline European & Capital Goods & 0.11 & 0.11 & 0.09 & 0.09 & 0.02 & 0.02 & 0.03 & 0.02 & 0.02 & 0.02 & 0.00 & 0.01 & 0.00 & 0.00 & 0.00 & 0.44 \\
\hline \multirow[t]{3}{*}{ Countries } & Consumer Goods & 0.15 & 0.10 & 0.12 & 0.09 & 0.03 & 0.03 & 0.03 & 0.03 & 0.02 & 0.02 & 0.01 & 0.00 & 0.01 & 0.00 & 0.00 & 0.36 \\
\hline & Energy & 0.05 & 0.16 & 0.21 & 0.04 & 0.03 & 0.15 & 0.02 & 0.07 & 0.03 & 0.05 & 0.02 & 0.01 & 0.03 & 0.02 & 0.00 & 0.11 \\
\hline & Financials & 0.12 & 0.09 & 0.08 & 0.09 & 0.05 & 0.04 & 0.03 & 0.02 & 0.02 & 0.01 & 0.01 & 0.01 & 0.01 & 0.00 & 0.00 & 0.43 \\
\hline \multirow[t]{6}{*}{ Australasia } & Basic Industries & 0.21 & 0.08 & 0.05 & 0.07 & 0.02 & 0.02 & 0.02 & 0.01 & 0.01 & 0.01 & 0.00 & 0.00 & 0.00 & 0.00 & 0.00 & 0.49 \\
\hline & Capital Goods & 0.07 & 0.07 & 0.12 & 0.09 & 0.01 & 0.01 & 0.01 & 0.02 & 0.01 & 0.02 & 0.00 & 0.00 & 0.00 & 0.00 & 0.00 & 0.56 \\
\hline & Consumer Goods & 0.12 & 0.05 & 0.12 & 0.09 & 0.01 & 0.03 & 0.02 & 0.01 & 0.01 & 0.02 & 0.00 & 0.00 & 0.00 & 0.00 & 0.00 & 0.50 \\
\hline & Energy & 0.07 & 0.14 & 0.06 & 0.06 & 0.02 & 0.01 & 0.01 & 0.01 & 0.01 & 0.01 & 0.00 & 0.00 & 0.00 & 0.00 & 0.00 & 0.61 \\
\hline & Financials & 0.17 & 0.09 & 0.04 & 0.14 & 0.05 & 0.03 & 0.03 & 0.01 & 0.02 & 0.01 & 0.01 & 0.01 & 0.00 & 0.00 & 0.00 & 0.38 \\
\hline & Others & 0.13 & 0.13 & 0.06 & 0.09 & 0.03 & 0.02 & 0.02 & 0.02 & 0.02 & 0.01 & 0.00 & 0.01 & 0.00 & 0.00 & 0.00 & 0.45 \\
\hline Asian & Basic Industries & 0.14 & 0.08 & 0.05 & 0.07 & 0.02 & 0.01 & 0.02 & 0.01 & 0.01 & 0.01 & 0.00 & 0.00 & 0.00 & 0.00 & 0.00 & 0.58 \\
\hline \multirow[t]{5}{*}{ Countries } & Capital Goods & 0.11 & 0.10 & 0.04 & 0.11 & 0.04 & 0.02 & 0.07 & 0.03 & 0.11 & 0.01 & 0.01 & 0.04 & 0.01 & 0.06 & 0.04 & 0.20 \\
\hline & Consumer Goods & 0.08 & 0.08 & 0.07 & 0.14 & 0.03 & 0.01 & 0.03 & 0.02 & 0.06 & 0.05 & 0.01 & 0.01 & 0.01 & 0.03 & 0.01 & 0.36 \\
\hline & Energy & 0.37 & 0.03 & 0.04 & 0.02 & 0.11 & 0.09 & 0.04 & 0.01 & 0.00 & 0.00 & 0.04 & 0.01 & 0.01 & 0.00 & 0.00 & 0.21 \\
\hline & Financials & 0.08 & 0.12 & 0.07 & 0.12 & 0.02 & 0.01 & 0.02 & 0.03 & 0.05 & 0.02 & 0.01 & 0.01 & 0.01 & 0.01 & 0.00 & 0.42 \\
\hline & Others & 0.13 & 0.10 & 0.05 & 0.09 & 0.04 & 0.03 & 0.04 & 0.03 & 0.08 & 0.02 & 0.02 & 0.03 & 0.01 & 0.04 & 0.02 & 0.28 \\
\hline \multicolumn{2}{|l|}{ Average } & 0.12 & 0.10 & 0.09 & 0.09 & 0.03 & 0.03 & 0.03 & 0.02 & 0.03 & 0.02 & 0.01 & 0.01 & 0.01 & 0.01 & 0.00 & 0.40 \\
\hline
\end{tabular}

Notes: Bolded numbers represent the highest posterior probability in each country/sector grid or the posterior probability which is larger than or equal to 0.2 . 
Table 5 Posterior Probabilities of 16 Combinations of FMPs for Country - Sector Grids

Equally Weighted Returns and Standardised for Different Accounting Regimes of Different Countries

\begin{tabular}{|c|c|c|c|c|c|c|c|c|c|c|c|c|c|c|c|c|}
\hline Country & FVL & FGR & FDE & FSZ & $\begin{array}{l}\text { FVL, } \\
\text { FGR }\end{array}$ & $\begin{array}{l}\text { FVL, } \\
\text { FDE }\end{array}$ & $\begin{array}{l}\text { FVL, } \\
\text { FSZ }\end{array}$ & $\begin{array}{l}\text { FGR, } \\
\text { FDE }\end{array}$ & $\begin{array}{c}\text { FGR, } \\
\text { FSZ }\end{array}$ & $\begin{array}{c}\text { FDE, } \\
\text { FSZ }\end{array}$ & $\begin{array}{c}\text { FVL, } \\
\text { FGR, FDE }\end{array}$ & $\begin{array}{c}\text { FVL, } \\
\text { FGR, FSZ }\end{array}$ & $\begin{array}{l}\text { FVL, FDE, } \\
\text { FSZ }\end{array}$ & $\begin{array}{c}\text { FGR, } \\
\text { FDE, FSZ }\end{array}$ & $\begin{array}{c}\text { FVL, FGR, } \\
\text { FDE, FSZ }\end{array}$ & None \\
\hline Canada & 0.11 & 0.11 & 0.09 & 0.08 & 0.03 & 0.02 & 0.02 & 0.04 & 0.03 & 0.02 & 0.01 & 0.01 & 0.00 & 0.01 & 0.00 & 0.42 \\
\hline France & 0.17 & 0.10 & 0.07 & 0.08 & 0.03 & 0.03 & 0.03 & 0.01 & 0.02 & 0.02 & 0.00 & 0.01 & 0.00 & 0.00 & 0.00 & 0.42 \\
\hline Germany & 0.10 & 0.14 & 0.08 & 0.07 & 0.02 & 0.02 & 0.02 & 0.03 & 0.02 & 0.01 & 0.01 & 0.00 & 0.00 & 0.00 & 0.00 & 0.46 \\
\hline Japan & 0.07 & 0.08 & 0.09 & 0.13 & 0.03 & 0.03 & 0.08 & 0.03 & 0.04 & 0.07 & 0.01 & 0.02 & 0.04 & 0.03 & 0.01 & 0.24 \\
\hline UK & 0.10 & 0.13 & 0.08 & 0.08 & 0.03 & 0.02 & 0.02 & 0.02 & 0.02 & 0.01 & 0.01 & 0.01 & 0.01 & 0.00 & 0.00 & 0.46 \\
\hline US & 0.12 & 0.09 & 0.08 & 0.12 & 0.03 & 0.03 & 0.03 & 0.02 & 0.03 & 0.03 & 0.01 & 0.01 & 0.01 & 0.01 & 0.00 & 0.39 \\
\hline Other European Countries & 0.12 & 0.11 & 0.10 & 0.09 & 0.03 & 0.05 & 0.03 & 0.03 & 0.03 & 0.02 & 0.01 & 0.01 & 0.01 & 0.01 & 0.00 & 0.37 \\
\hline Australasia & 0.11 & 0.10 & 0.08 & 0.09 & 0.03 & 0.02 & 0.02 & 0.01 & 0.02 & 0.01 & 0.00 & 0.00 & 0.00 & 0.00 & 0.00 & 0.51 \\
\hline Asian Countries & 0.15 & 0.08 & 0.05 & 0.10 & 0.04 & 0.04 & 0.03 & 0.02 & 0.07 & 0.02 & 0.02 & 0.02 & 0.01 & 0.03 & 0.01 & 0.31 \\
\hline
\end{tabular}

\section{B. Posterior Probabilities of 16 Combinations of FMPs Averaged over Sectors}

\begin{tabular}{|c|c|c|c|c|c|c|c|c|c|c|c|c|c|c|c|c|}
\hline Sector & FVL & FGR & FDE & FSZ & $\begin{array}{l}\text { FVL, } \\
\text { FGR }\end{array}$ & $\begin{array}{l}\text { FVL, } \\
\text { FDE }\end{array}$ & $\begin{array}{l}\text { FVL, } \\
\text { FSZ }\end{array}$ & $\begin{array}{l}\text { FGR, } \\
\text { FDE }\end{array}$ & $\begin{array}{l}\text { FGR, } \\
\text { FSZ }\end{array}$ & $\begin{array}{l}\text { FDE, } \\
\text { FSZ }\end{array}$ & $\begin{array}{c}\text { FVL, } \\
\text { FGR, FDE }\end{array}$ & $\begin{array}{c}\text { FVL, } \\
\text { FGR, FSZ }\end{array}$ & $\begin{array}{c}\text { FVL, FDE, } \\
\text { FSZ }\end{array}$ & $\begin{array}{c}\text { FGR, } \\
\text { FDE, FSZ }\end{array}$ & $\begin{array}{l}\text { FVL, FGR, } \\
\text { FDE, FSZ }\end{array}$ & None \\
\hline Basic Industries & 0.12 & 0.08 & 0.07 & 0.10 & 0.02 & 0.02 & 0.03 & 0.02 & 0.02 & 0.02 & 0.00 & 0.00 & 0.01 & 0.00 & 0.00 & $\overline{0.48}$ \\
\hline Capital Goods & 0.10 & 0.09 & 0.09 & 0.09 & 0.03 & 0.03 & 0.03 & 0.03 & 0.03 & 0.03 & 0.01 & 0.01 & 0.01 & 0.02 & 0.01 & 0.39 \\
\hline Consumer Goods & 0.11 & 0.09 & 0.09 & 0.10 & 0.03 & 0.02 & 0.03 & 0.02 & 0.03 & 0.03 & 0.01 & 0.01 & 0.01 & 0.01 & 0.00 & 0.41 \\
\hline Energy & 0.16 & 0.12 & 0.08 & 0.06 & 0.05 & 0.05 & 0.02 & 0.03 & 0.02 & 0.01 & 0.02 & 0.01 & 0.01 & 0.01 & 0.00 & 0.36 \\
\hline Financials & 0.10 & 0.11 & 0.08 & 0.12 & 0.03 & 0.03 & 0.04 & 0.03 & 0.03 & 0.03 & 0.01 & 0.01 & 0.01 & 0.01 & 0.00 & 0.38 \\
\hline Others & 0.11 & 0.13 & 0.07 & 0.09 & 0.04 & 0.02 & 0.04 & 0.02 & 0.04 & 0.02 & 0.01 & 0.02 & 0.01 & 0.01 & 0.01 & 0.36 \\
\hline
\end{tabular}




\section{Posterior Probabilities of 16 Combinations of FMPs for Country - Sector Grids}

\begin{tabular}{|c|c|c|c|c|c|c|c|c|c|c|c|c|c|c|c|c|c|}
\hline Country & Sector & FVL & FGR & FDE & FSZ & $\begin{array}{l}\text { FVL, } \\
\text { FGR }\end{array}$ & $\begin{array}{l}\text { FVL, } \\
\text { FDE }\end{array}$ & $\begin{array}{l}\text { FVL, } \\
\text { FSZ }\end{array}$ & $\begin{array}{l}\text { FGR, } \\
\text { FDE }\end{array}$ & $\begin{array}{l}\text { FGR, } \\
\text { FSZ }\end{array}$ & $\begin{array}{l}\text { FDE, } \\
\text { FSZ }\end{array}$ & $\begin{array}{c}\text { FVL, } \\
\text { FGR, FDE }\end{array}$ & $\begin{array}{c}\text { FVL, } \\
\text { FGR, FSZ }\end{array}$ & $\begin{array}{l}\text { FVL, FDE, } \\
\text { FSZ }\end{array}$ & $\begin{array}{c}\text { FGR, } \\
\text { FDE, FSZ }\end{array}$ & $\begin{array}{c}\text { FVL, FGR, } \\
\text { FDE, FSZ }\end{array}$ & None \\
\hline \multirow[t]{6}{*}{ Canada } & Basic Industries & 0.08 & 0.07 & 0.11 & 0.07 & 0.01 & 0.01 & 0.01 & 0.01 & 0.01 & 0.01 & 0.00 & 0.00 & 0.00 & 0.00 & 0.00 & 0.60 \\
\hline & Capital Goods & 0.22 & 0.08 & 0.07 & 0.05 & 0.03 & 0.03 & 0.02 & 0.01 & 0.01 & 0.01 & 0.00 & 0.00 & 0.00 & 0.00 & 0.00 & 0.45 \\
\hline & Consumer Goods & 0.13 & 0.10 & 0.09 & 0.09 & 0.02 & 0.02 & 0.02 & 0.03 & 0.01 & 0.01 & 0.00 & 0.00 & 0.00 & 0.00 & 0.00 & 0.45 \\
\hline & Energy & 0.08 & 0.22 & 0.04 & 0.09 & 0.04 & 0.01 & 0.02 & 0.05 & 0.05 & 0.01 & 0.01 & 0.01 & 0.00 & 0.01 & 0.00 & 0.35 \\
\hline & Financials & 0.05 & 0.06 & 0.17 & 0.08 & 0.01 & 0.03 & 0.01 & 0.12 & 0.01 & 0.03 & 0.01 & 0.00 & 0.01 & 0.03 & 0.00 & 0.38 \\
\hline & Others & 0.09 & 0.14 & 0.04 & 0.08 & 0.09 & 0.01 & 0.03 & 0.02 & 0.06 & 0.01 & 0.02 & 0.06 & 0.01 & 0.01 & 0.02 & 0.32 \\
\hline \multirow[t]{6}{*}{ France } & Basic Industries & & . & . & 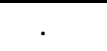 & . & 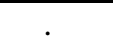 & ${ }^{\circ}$ & . & . & 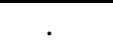 & & & & & & 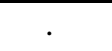 \\
\hline & Capital Goods & 0.10 & 0.09 & 0.14 & 0.10 & 0.03 & 0.02 & 0.02 & 0.02 & 0.02 & 0.03 & 0.00 & 0.01 & 0.01 & 0.01 & 0.00 & 0.39 \\
\hline & Consumer Goods & 0.10 & 0.13 & 0.07 & 0.07 & 0.05 & 0.02 & 0.02 & 0.02 & 0.02 & 0.01 & 0.01 & 0.01 & 0.00 & 0.00 & 0.00 & 0.46 \\
\hline & Energy & 0.35 & 0.07 & 0.04 & 0.03 & 0.05 & 0.05 & 0.04 & 0.01 & 0.01 & 0.00 & 0.01 & 0.01 & 0.01 & 0.00 & 0.00 & 0.32 \\
\hline & Financials & 0.13 & 0.10 & 0.05 & 0.14 & 0.02 & 0.02 & 0.02 & 0.01 & 0.02 & 0.02 & 0.00 & 0.00 & 0.00 & 0.00 & 0.00 & 0.45 \\
\hline & Others & 0.17 & 0.12 & 0.05 & 0.07 & 0.03 & 0.02 & 0.02 & 0.01 & 0.02 & 0.01 & 0.00 & 0.00 & 0.00 & 0.00 & 0.00 & 0.45 \\
\hline \multirow[t]{6}{*}{ Germany } & Basic Industries & 0.08 & 0.08 & 0.06 & 0.07 & 0.01 & 0.01 & 0.01 & 0.01 & 0.01 & 0.01 & 0.00 & 0.00 & 0.00 & 0.00 & 0.00 & 0.67 \\
\hline & Capital Goods & 0.07 & 0.11 & 0.11 & 0.10 & 0.02 & 0.03 & 0.02 & 0.06 & 0.02 & 0.02 & 0.01 & 0.00 & 0.00 & 0.01 & 0.00 & 0.42 \\
\hline & Consumer Goods & 0.10 & 0.14 & 0.09 & 0.07 & 0.03 & 0.02 & 0.01 & 0.02 & 0.02 & 0.01 & 0.00 & 0.00 & 0.00 & 0.00 & 0.00 & 0.48 \\
\hline & Energy & & & & $\cdot$ & & & & & & & & & & & & 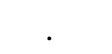 \\
\hline & Financials & 0.09 & 0.16 & 0.05 & 0.10 & 0.02 & 0.01 & 0.02 & 0.02 & 0.03 & 0.01 & 0.00 & 0.01 & 0.00 & 0.00 & 0.00 & 0.46 \\
\hline & Others & 0.15 & 0.23 & 0.09 & 0.03 & 0.05 & 0.05 & 0.01 & 0.05 & 0.02 & 0.01 & 0.01 & 0.00 & 0.01 & 0.01 & 0.00 & 0.29 \\
\hline \multirow[t]{6}{*}{ Japan } & Basic Industries & 0.06 & 0.07 & 0.08 & 0.20 & 0.02 & 0.01 & 0.06 & 0.04 & 0.04 & 0.06 & 0.01 & 0.01 & 0.02 & 0.02 & 0.01 & 0.29 \\
\hline & Capital Goods & 0.06 & 0.04 & 0.10 & 0.14 & 0.01 & 0.04 & 0.08 & 0.02 & 0.04 & 0.13 & 0.01 & 0.02 & 0.07 & 0.03 & 0.02 & 0.19 \\
\hline & Consumer Goods & 0.07 & 0.06 & 0.09 & 0.13 & 0.03 & 0.03 & 0.08 & 0.03 & 0.04 & 0.06 & 0.01 & 0.03 & 0.03 & 0.03 & 0.02 & 0.25 \\
\hline & Energy & 0.06 & 0.14 & 0.14 & 0.06 & 0.03 & 0.03 & 0.01 & 0.05 & 0.02 & 0.02 & 0.01 & 0.00 & 0.00 & 0.01 & 0.00 & 0.41 \\
\hline & Financials & 0.08 & 0.05 & 0.09 & 0.12 & 0.03 & 0.06 & 0.11 & 0.02 & 0.03 & 0.09 & 0.01 & 0.03 & 0.06 & 0.05 & 0.02 & 0.13 \\
\hline & Others & 0.11 & 0.12 & 0.05 & 0.09 & 0.04 & 0.02 & 0.12 & 0.02 & 0.05 & 0.06 & 0.01 & 0.03 & 0.06 & 0.03 & 0.01 & 0.18 \\
\hline
\end{tabular}




\begin{tabular}{|c|c|c|c|c|c|c|c|c|c|c|c|c|c|c|c|c|c|}
\hline \multirow[t]{5}{*}{ UK } & $\begin{array}{l}\text { Basic Industries } \\
\text { Capital Goods }\end{array}$ & 0.12 & 0.14 & $\dot{0} 0.06$ & $\dot{0} 07$ & 0.03 & $\dot{0} 0.02$ & 0.03 & 0.03 & 0.03 & 0.01 & 0.01 & 0.01 & 0.01 & 0.01 & 0.01 & 0.42 \\
\hline & Consumer Goods & 0.13 & 0.10 & 0.09 & 0.07 & 0.04 & 0.03 & 0.02 & 0.02 & 0.02 & 0.02 & 0.01 & 0.01 & 0.00 & 0.00 & 0.00 & 0.45 \\
\hline & Energy & 0.08 & 0.13 & 0.12 & 0.05 & 0.03 & 0.03 & 0.01 & 0.02 & 0.01 & 0.01 & 0.01 & 0.00 & 0.00 & 0.00 & 0.00 & 0.48 \\
\hline & Financials & 0.08 & 0.17 & 0.07 & 0.10 & 0.02 & 0.01 & 0.02 & 0.02 & 0.03 & 0.01 & 0.00 & 0.00 & 0.00 & 0.00 & 0.00 & 0.45 \\
\hline & Others & 0.12 & 0.09 & 0.06 & 0.09 & 0.02 & 0.01 & 0.04 & 0.01 & 0.01 & 0.01 & 0.00 & 0.01 & 0.01 & 0.00 & 0.00 & 0.51 \\
\hline \multirow[t]{6}{*}{ US } & Basic Industries & 0.17 & 0.08 & 0.06 & 0.10 & 0.04 & 0.04 & 0.04 & 0.01 & 0.02 & 0.01 & 0.01 & 0.01 & 0.01 & 0.00 & 0.00 & 0.39 \\
\hline & Capital Goods & 0.11 & 0.11 & 0.10 & 0.10 & 0.04 & 0.02 & 0.03 & 0.03 & 0.03 & 0.02 & 0.01 & 0.01 & 0.01 & 0.01 & 0.00 & 0.37 \\
\hline & Consumer Goods & 0.18 & 0.08 & 0.08 & 0.09 & 0.03 & 0.03 & 0.04 & 0.02 & 0.02 & 0.02 & 0.01 & 0.01 & 0.01 & 0.01 & 0.00 & 0.39 \\
\hline & Energy & 0.06 & 0.10 & 0.08 & 0.15 & 0.02 & 0.01 & 0.02 & 0.02 & 0.03 & 0.04 & 0.01 & 0.01 & 0.01 & 0.01 & 0.00 & 0.43 \\
\hline & Financials & 0.10 & 0.09 & 0.09 & 0.15 & 0.02 & 0.03 & 0.04 & 0.02 & 0.02 & 0.03 & 0.01 & 0.01 & 0.01 & 0.00 & 0.00 & 0.38 \\
\hline & Others & 0.10 & 0.10 & 0.10 & 0.14 & 0.03 & 0.02 & 0.03 & 0.02 & 0.03 & 0.04 & 0.01 & 0.01 & 0.01 & 0.01 & 0.00 & 0.36 \\
\hline Other & Basic Industries & 0.11 & 0.11 & 0.11 & 0.14 & 0.02 & 0.02 & 0.02 & 0.03 & 0.04 & 0.03 & 0.00 & 0.01 & 0.00 & 0.01 & 0.00 & 0.35 \\
\hline European & Capital Goods & 0.11 & 0.11 & 0.08 & 0.10 & 0.03 & 0.02 & 0.03 & 0.02 & 0.02 & 0.02 & 0.01 & 0.01 & 0.00 & 0.00 & 0.00 & 0.44 \\
\hline \multirow[t]{4}{*}{ Countries } & Consumer Goods & 0.16 & 0.09 & 0.12 & 0.09 & 0.02 & 0.03 & 0.03 & 0.02 & 0.01 & 0.02 & 0.00 & 0.00 & 0.01 & 0.00 & 0.00 & 0.39 \\
\hline & Energy & 0.13 & 0.12 & 0.10 & 0.04 & 0.04 & 0.16 & 0.03 & 0.07 & 0.06 & 0.01 & 0.04 & 0.01 & 0.02 & 0.01 & 0.00 & 0.16 \\
\hline & Financials & 0.11 & 0.09 & 0.08 & 0.09 & 0.06 & 0.04 & 0.03 & 0.02 & 0.02 & 0.01 & 0.01 & 0.01 & 0.01 & 0.00 & 0.00 & 0.42 \\
\hline & Others & 0.07 & 0.11 & 0.11 & 0.12 & 0.02 & 0.01 & 0.02 & 0.02 & 0.03 & 0.02 & 0.00 & 0.00 & 0.00 & 0.00 & 0.00 & 0.46 \\
\hline \multirow[t]{6}{*}{ Australasia } & Basic Industries & 0.18 & 0.08 & 0.05 & 0.07 & 0.02 & 0.02 & 0.02 & 0.01 & 0.01 & 0.01 & 0.00 & 0.00 & 0.00 & 0.00 & 0.00 & 0.53 \\
\hline & Capital Goods & 0.07 & 0.07 & 0.12 & 0.08 & 0.01 & 0.02 & 0.01 & 0.02 & 0.01 & 0.02 & 0.00 & 0.00 & 0.00 & 0.00 & 0.00 & 0.56 \\
\hline & Consumer Goods & 0.08 & 0.06 & 0.13 & 0.11 & 0.01 & 0.02 & 0.01 & 0.02 & 0.01 & 0.02 & 0.00 & 0.00 & 0.00 & 0.00 & 0.00 & 0.53 \\
\hline & Energy & 0.07 & 0.15 & 0.06 & 0.05 & 0.02 & 0.01 & 0.01 & 0.01 & 0.01 & 0.01 & 0.00 & 0.00 & 0.00 & 0.00 & 0.00 & 0.60 \\
\hline & Financials & 0.13 & 0.11 & 0.04 & 0.14 & 0.06 & 0.03 & 0.03 & 0.01 & 0.03 & 0.01 & 0.01 & 0.01 & 0.00 & 0.00 & 0.00 & 0.38 \\
\hline & Others & 0.12 & 0.15 & 0.06 & 0.08 & 0.03 & 0.01 & 0.02 & 0.02 & 0.02 & 0.01 & 0.00 & 0.01 & 0.00 & 0.00 & 0.00 & 0.45 \\
\hline Asian & Basic Industries & 0.15 & 0.07 & 0.05 & 0.08 & 0.02 & 0.01 & 0.02 & 0.01 & 0.01 & 0.01 & 0.00 & 0.00 & 0.00 & 0.00 & 0.00 & 0.57 \\
\hline \multirow[t]{5}{*}{ Countries } & Capital Goods & 0.08 & 0.09 & 0.05 & 0.07 & 0.04 & 0.04 & 0.02 & 0.03 & 0.10 & 0.03 & 0.02 & 0.04 & 0.01 & 0.08 & 0.02 & 0.30 \\
\hline & Consumer Goods & 0.07 & 0.06 & 0.08 & 0.19 & 0.02 & 0.02 & 0.04 & 0.02 & 0.08 & 0.05 & 0.01 & 0.02 & 0.01 & 0.03 & 0.01 & 0.31 \\
\hline & Energy & 0.43 & 0.02 & 0.02 & 0.01 & 0.14 & 0.11 & 0.05 & 0.00 & 0.00 & 0.00 & 0.05 & 0.01 & 0.02 & 0.00 & 0.01 & 0.12 \\
\hline & Financials & 0.07 & 0.13 & 0.07 & 0.14 & 0.02 & 0.02 & 0.03 & 0.04 & 0.07 & 0.02 & 0.01 & 0.01 & 0.00 & 0.01 & 0.00 & 0.36 \\
\hline & Others & 0.09 & 0.11 & 0.05 & 0.14 & 0.03 & 0.02 & 0.04 & 0.04 & 0.14 & 0.03 & 0.01 & 0.03 & 0.01 & 0.05 & 0.01 & 0.19 \\
\hline \multicolumn{2}{|l|}{ Average } & 0.12 & 0.10 & 0.08 & 0.09 & 0.03 & 0.03 & 0.03 & 0.02 & 0.03 & 0.02 & 0.01 & 0.01 & 0.01 & 0.01 & 0.00 & 0.39 \\
\hline
\end{tabular}

Notes: Bolded numbers represent the highest posterior probability in each country/sector grid or the posterior probability which is larger than or equal to 0.2 . 
Figure 1 Posterior Probability of FMPs in Some Country - Sector Grids

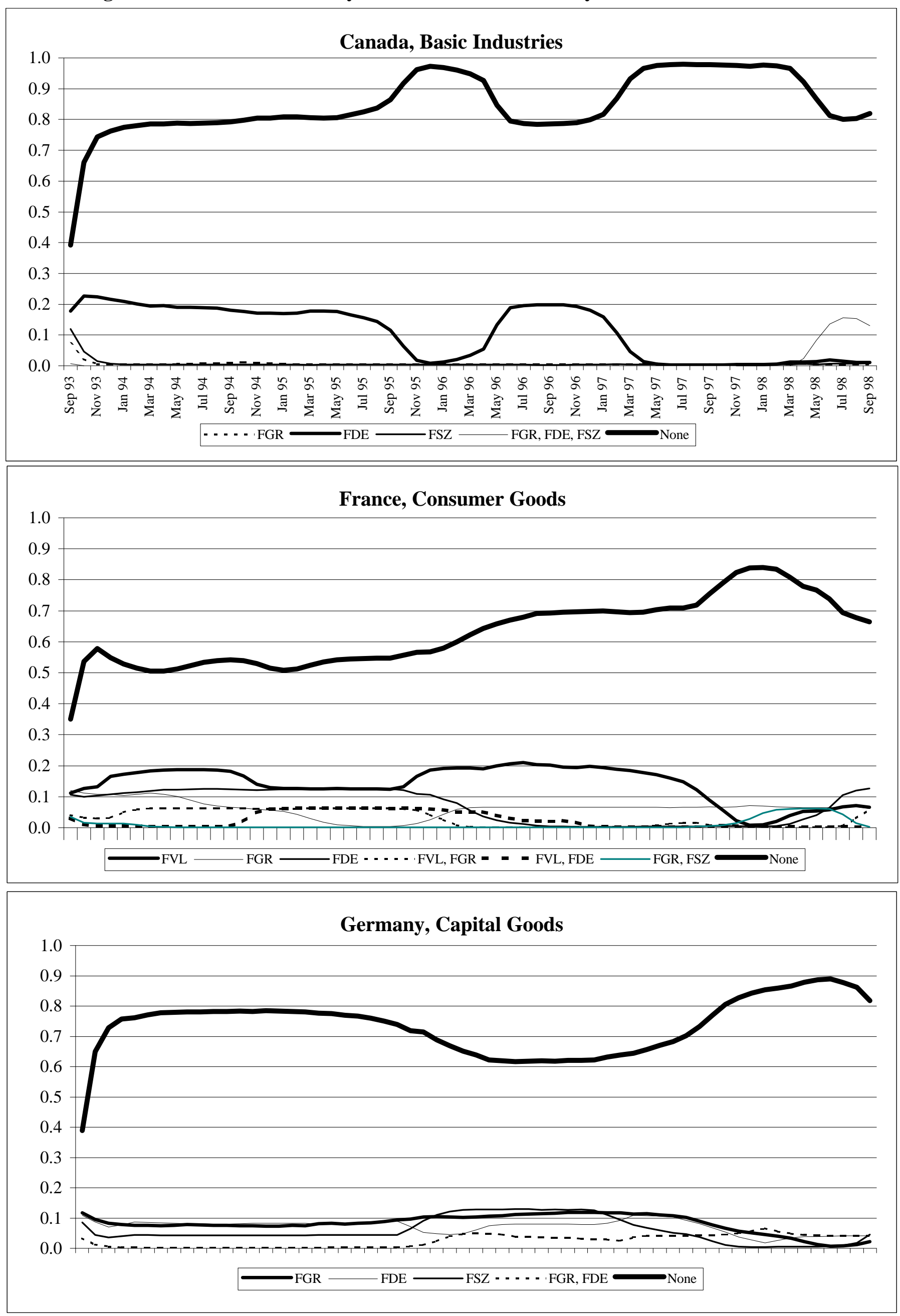



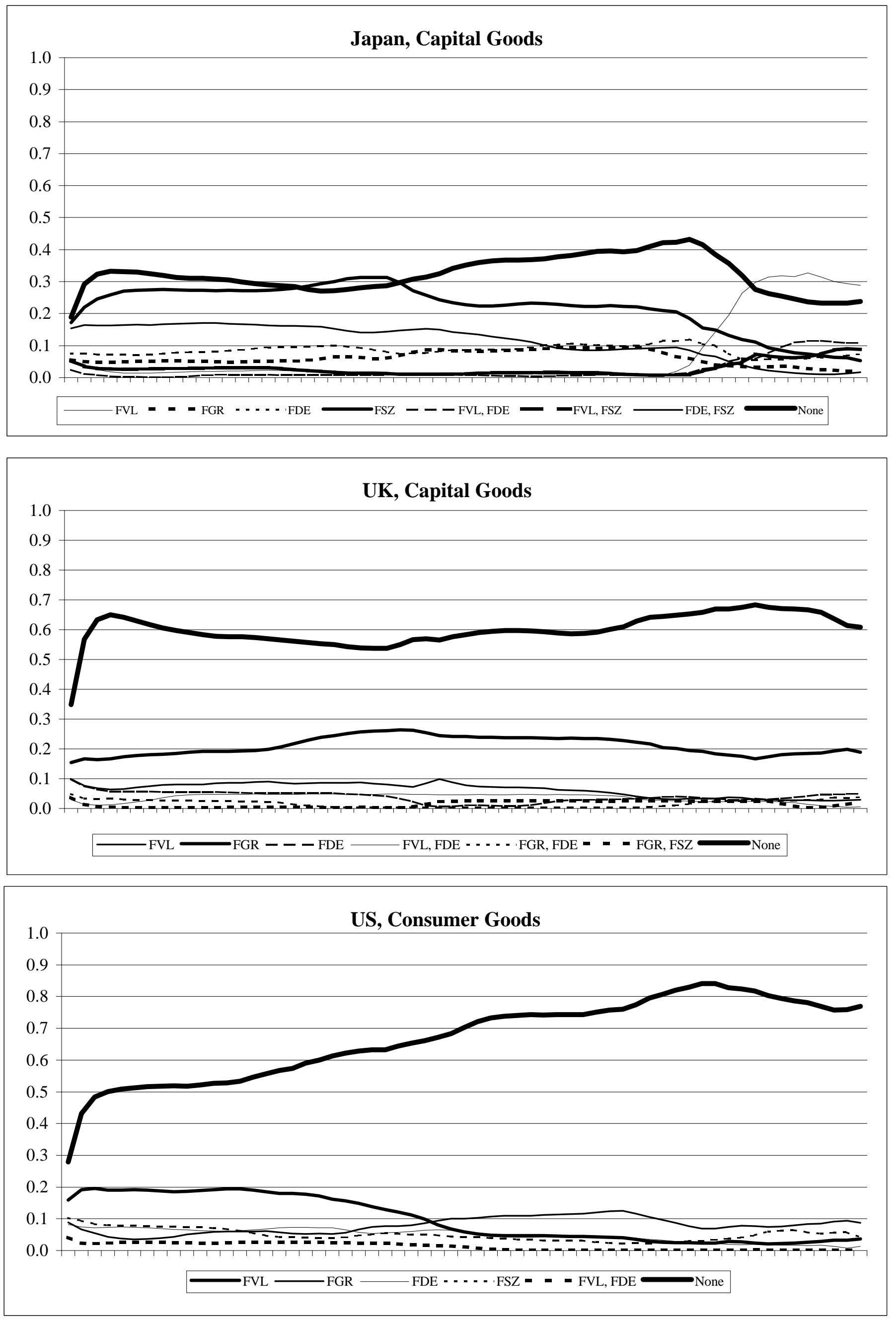

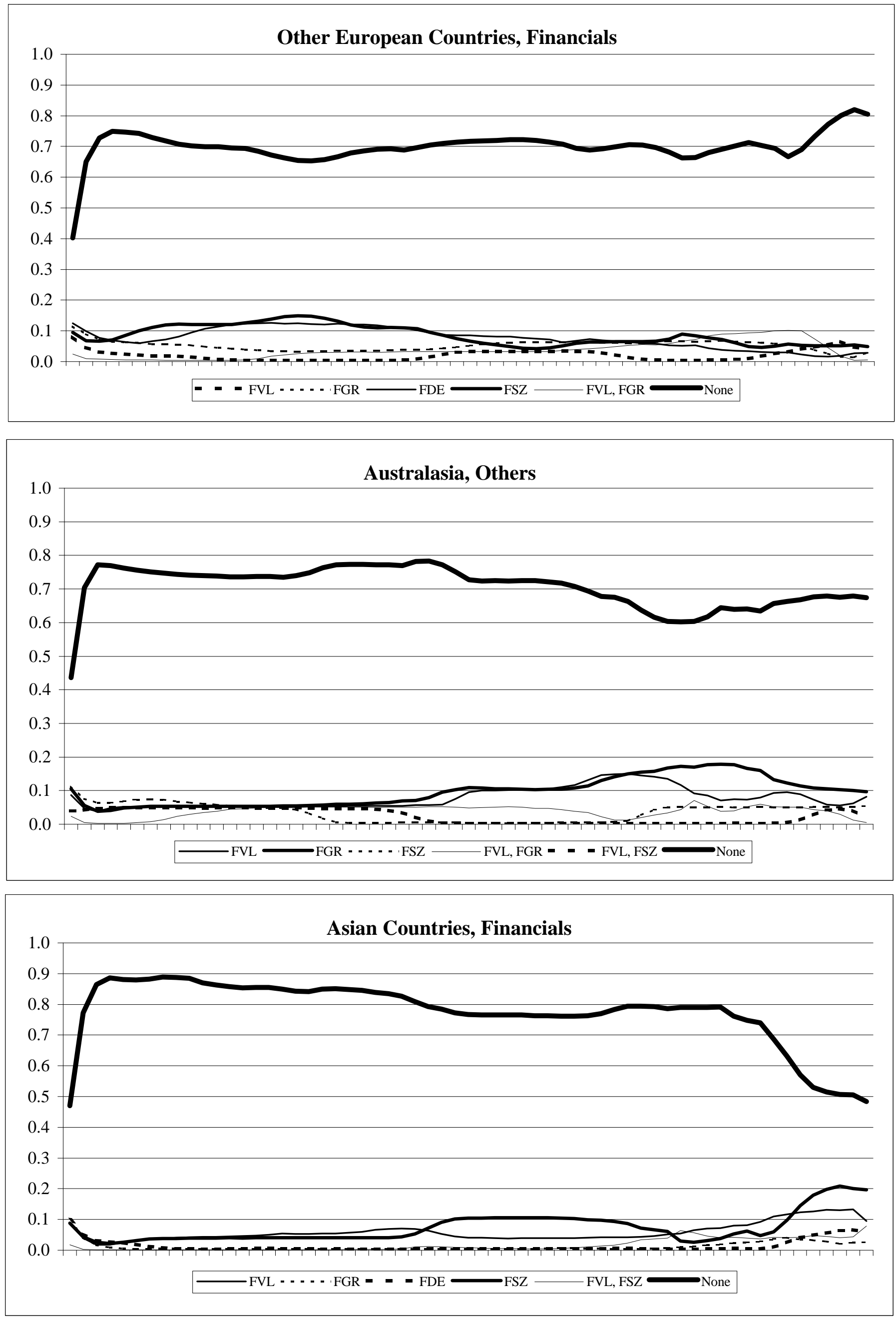